\title{
Methodology for Evaluating Cost-Effectiveness of Commercial Energy Code Changes
}

R. Hart, B. Liu

August 2015

Prepared by Pacific Northwest National Laboratory 


\title{
DISCLAIMER
}

This report was prepared as an account of work sponsored by an agency of the United States Government. Neither the United States Government nor any agency thereof, nor Battelle Memorial Institute, nor any of their employees, makes any warranty, express or implied, or assumes any legal liability or responsibility for the accuracy, completeness, or usefulness of any information, apparatus, product, or process disclosed, or represents that its use would not infringe privately owned rights. Reference herein to any specific commercial product, process, or service by trade name, trademark, manufacturer, or otherwise does not necessarily constitute or imply its endorsement, recommendation, or favoring by the United States Government or any agency thereof, or Battelle Memorial Institute. The views and opinions of authors expressed herein do not necessarily state or reflect those of the United States Government or any agency thereof.

\author{
PACIFIC NORTHWEST NATIONAL LABORATORY \\ operated by \\ BATTELIE \\ for the \\ UNITED STATES DEPARTMENT OF ENERGY \\ under Contract DE-ACO5-76RLO1830 \\ Printed in the United States of America \\ Available to DOE and DOE contractors from the \\ Office of Scientific and Technical Information,
P.O. Box 62, Oak Ridge, TN 37831-0062; \\ ph: (865) 576-8401 \\ email: reports@adonis.osti.gov \\ Available to the public from the National Technical Information Service, \\ U.S. Department of Commerce, 5285 Port Royal Rd., Springfield, VA 2216 \\ ph: (800) 553-6847
fax: $(703) 605-6900$ \\ email: orders@ $@$ ntis.fedworld.gov \\ online ordering: http://www.ntis.gov/ordering.htm
}

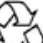

This document was printed on recycled paper.

(9/2003) 


\section{Methodology for Evaluating Cost- effectiveness of Commercial Energy Code Changes}

R Hart

B Liu

August 2015

Prepared for

the U.S. Department of Energy

under Contract DE-AC05-76RL01830

Prepared by

Pacific Northwest National Laboratory

Richland, Washington 99352 



\section{Summary}

This document lays out the U.S. Department of Energy's (DOE's) methodology for evaluating the cost-effectiveness of energy code and standard ${ }^{1}$ proposals and editions. The evaluation is applied to new provisions or editions of ANSI/ASHRAE/IES ${ }^{2}$ Standard 90.1 and the International Energy Conservation Code. The methodology follows standard life-cycle cost (LCC) economic analysis procedures. Costeffectiveness evaluation requires three steps: 1) evaluating the energy and energy cost savings of code changes, 2) evaluating the incremental and replacement costs related to the changes, and 3) determining the cost-effectiveness of energy code changes based on those costs and savings over time.

Cost-effectiveness can be evaluated for an individual code change proposal or an entire edition-toedition upgrade of an energy code. Multiple parties are interested in building energy codes, and they have different economic viewpoints. To account for this, and the fact that the ASHRAE Standing Standard Project Committee (SSPC) 90.1 has established an economic analysis procedure, three scenarios have been established for the cost-effectiveness methodology:

1. Scenario 1 (also referred to as the Publicly-Owned Method): LCC analysis method representing government or public ownership (without borrowing or taxes).

2. Scenario 2 (also referred to as the Privately-Owned Method): LCC analysis method representing private or business ownership (includes loan and tax impacts).

3. Scenario 3 (also referred to as the ASHRAE 90.1 Scalar Method): Represents a pre-tax private investment point of view, and uses economic inputs established by the ASHRAE SSPC 90.1.

In evaluating code change proposals and assessing new editions of commercial building energy codes, DOE intends to calculate multiple metrics selected from the following:

- Life-cycle cost net savings (a.k.a., net present value (NPV) of savings)

- Savings-to-investment ratio (SIR)

- The ASHRAE 90.1 scalar ratio

- Simple payback period

NPV of savings based on LCC is the primary metric DOE intends to use to evaluate whether a particular code change is cost-effective. Any code change that results in an NPV of savings greater than to zero (i.e., monetary benefits exceed costs) will be considered cost-effective. The payback period, scalar ratio, and SIR analyses provide additional information DOE believes is helpful to other participants in code change processes and to states and jurisdictions considering adoption of a new code.

Economic parameters are chosen to represent the economic impact of a typical commercial building ownership or tenant situation. DOE's approach is to consult appropriate sources of publicly available information to establish assumptions for each financial, economic, and energy price parameter, following

\footnotetext{
${ }^{1}$ Throughout this document, when referring to energy codes, energy standards are included, as they become adopted into code, and are evaluated for their impact as an adopted code.

${ }^{2}$ ANSI - American National Standards Institute; ASHRAE - American Society of Heating, Refrigerating and AirConditioning Engineers; IES - Illuminating Engineering Society; IESNA - Illuminating Engineering Society of North America (IESNA rather than IES was identified with Standard 90.1 prior to 90.1-2010)
} 
the guidelines established in this methodology. DOE intends to update parameters for future analyses to account for changing economic conditions, and document the source of each parameter in the specific analysis. 


\section{Acknowledgments}

This report was prepared by Pacific Northwest National Laboratory (PNNL) for the U.S. Department of Energy (DOE) Building Energy Codes Program. The authors would like to thank David Cohan, Jeremy Williams, and Mohammed Khan at DOE for providing oversight. This work was truly a team effort, and the authors would like to express their deep appreciation to everyone from the PNNL codes team who contributed to its completion, including especially Michael Rosenberg, Matt Wilburn, Todd Taylor, Vrushali Mendon, and Mark Halverson.

Reid Hart, PE

Pacific Northwest National Laboratory 



\section{Acronyms and Abbreviations}

ANSI

ASHRAE

BECP

DEER

DOE

EIA

EISA

FEMP

HVAC

ICC

IECC

IES

LCC

MEP

MHC

NIST

NPV

PNNL

PPI

SIR

SSPC
American National Standards Institute

American Society of Heating, Refrigerating and Air-Conditioning Engineers

Building Energy Codes Program

Database for Energy Efficient Resources

U.S. Department of Energy

Energy Information Administration

Energy Independence and Security Act of 2007

Federal Energy Management Program

heating, ventilating, and air-conditioning

International Code Council

International Energy Conservation Code

Illuminating Engineering Society

life-cycle cost

mechanical, electrical, and plumbing

McGraw-Hill Construction

National Institute of Standards and Technology

net present value

Pacific Northwest National Laboratory

Producer Price Index

savings-to-investment ratio

Standing Standard Project Committee 



\section{Contents}

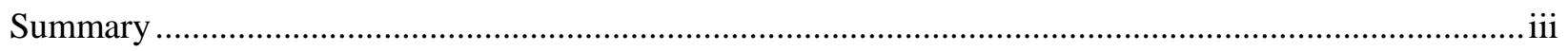

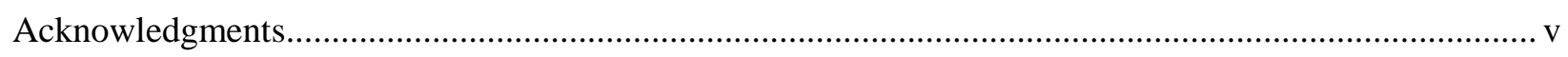

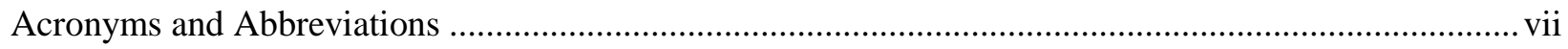

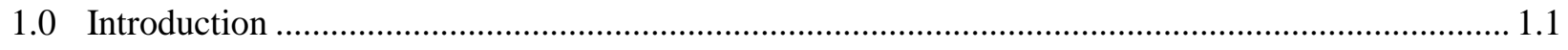

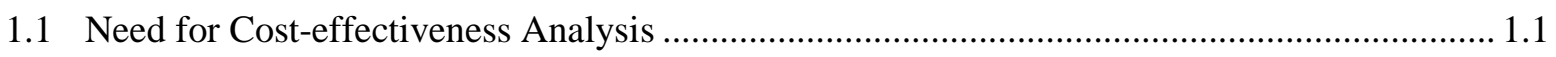

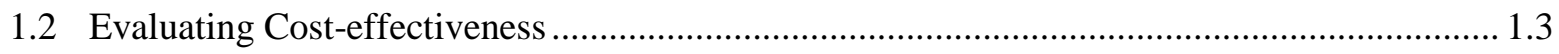

2.0 Estimating the Energy and Energy Cost Savings of Code Changes ............................................ 2.1

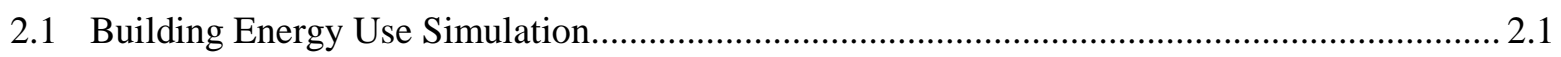

2.1.1 Energy Simulation Tool ….................................................................................. 2.1

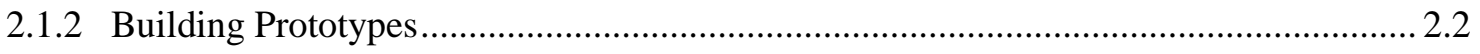

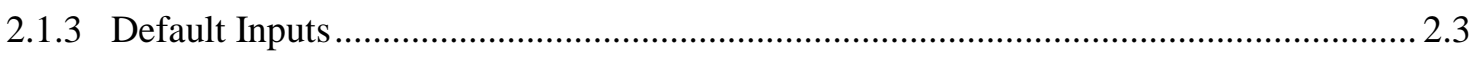

2.1.4 Provisions Requiring Special Consideration ............................................................. 2.4

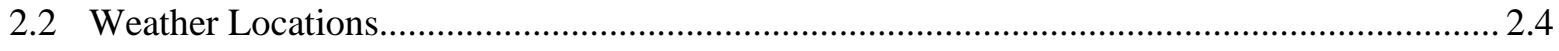

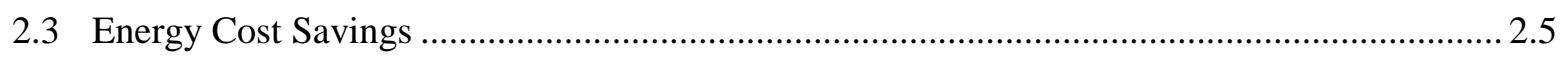

3.0 Estimating the Incremental Costs of Code Changes................................................................... 3.1

3.1 Cost Estimating Approach .......................................................................................... 3.1

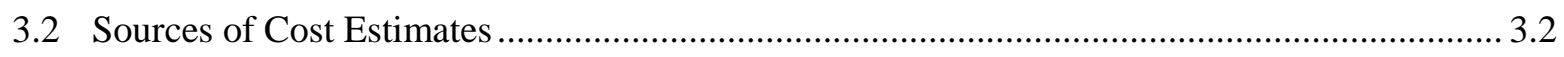

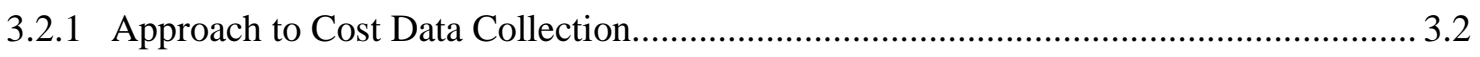

3.2.2 Economies of Scale and Market Transformation Effects............................................... 3.3

3.2.3 Addressing Code Changes with Multiple Approaches to Compliance ........................... 3.4

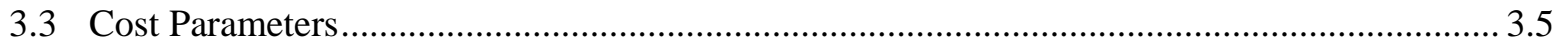

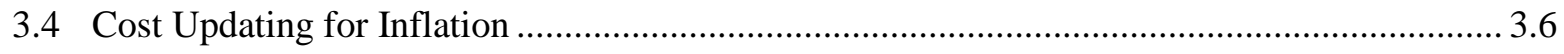

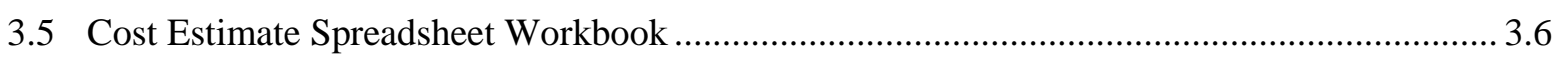

4.0 Estimating the Cost-effectiveness of Code Changes ...................................................................... 4.1

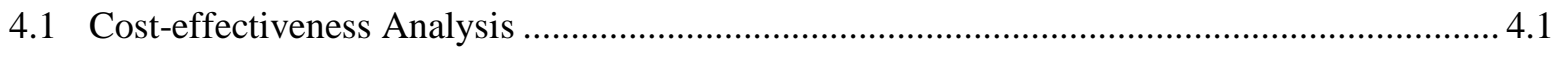

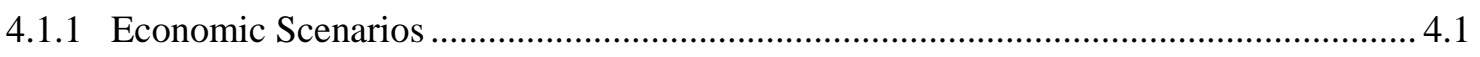

4.1.2 Cost-effectiveness Methodology ............................................................................. 4.2

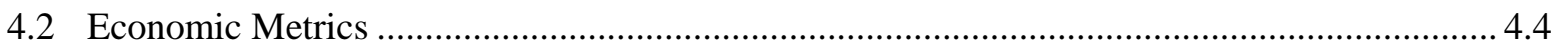

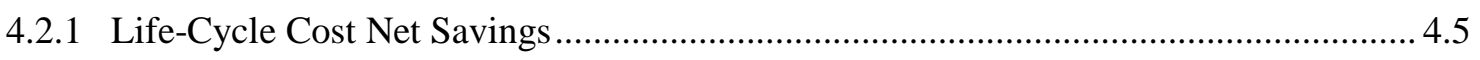

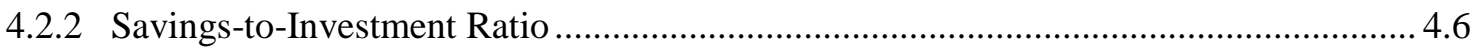

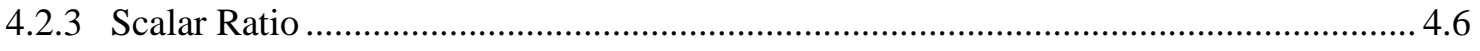

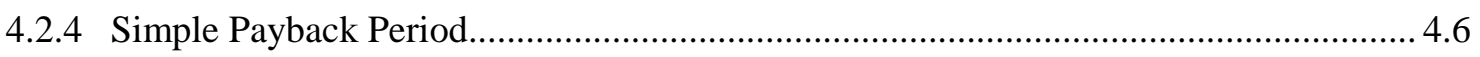

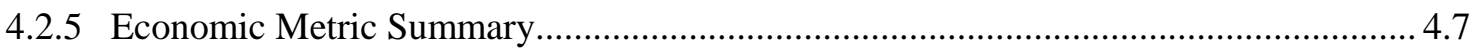

4.3 Economic Parameters and Other Inputs .............................................................................. 4.8

4.3.1 Scenario 1: Publicly-Owned Method Parameters......................................................... 4.9

4.3.2 Scenario 2: Privately-Owned Method Parameters .......................................................... 4.9 
4.3.3 Scenario 3: ASHRAE 90.1 Scalar Method Parameters.

4.3.4 Detailed Discussion of Economic Parameters.

5.0 Aggregating Energy and Economic Results ............................................................................... 5.1

5.1 Weighting Factors: Building Types and Climate Zones ..................................................... 5.1

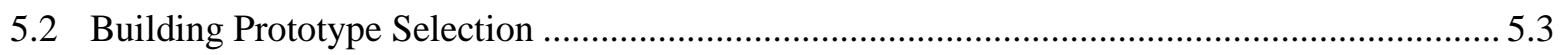

5.3 Represented HVAC Equipment Types............................................................................... 5.3

5.4 Aggregation across Building Type and Climate Zone ........................................................ 5.4

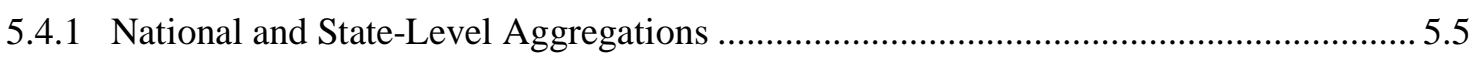

5.4.2 Demonstration of Aggregate Cost-effectiveness......................................................... 5.5

5.5 Supplemental Range of Results or Sensitivity Analysis .................................................... 5.5

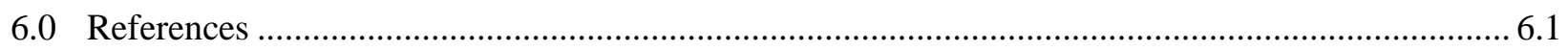

Appendix A Current Cost-effectiveness Parameters.............................................................................. A.1

Appendix B Supplemental Range of Results Method......................................................................... 


\section{Tables}

Table 2.1. Commercial Prototype Building Basic Characteristics........................................................ 2.3

Table 2.2. Climate Locations Used in Energy Simulations .................................................................. 2.5

Table 3.1. Example Sources of Cost Estimates by Cost Category.......................................................... 3.2

Table 3.2. Cost Estimate Adjustment Parameters ................................................................................. 3.5

Table 4.1. Economic Metrics ....................................................................................................... 4.7

Table 4.2. Economic Parameters Required for Cost-effectiveness Metrics............................................ 4.8

Table 4.3. Economic Parameters and Their Symbols ......................................................................... 4.9

Table 4.4. Present Value Cost and Benefit Components for Scenario 2............................................. 4.11

Table 4.5. Scalar Method Economic Parameters and Scalar Ratio Limit ............................................. 4.12

Table 5.1. National Weighting factors by Prototype........................................................................... 5.2

Table 5.2. Commercial Weighting Factors by Climate Zone ............................................................ 5.2

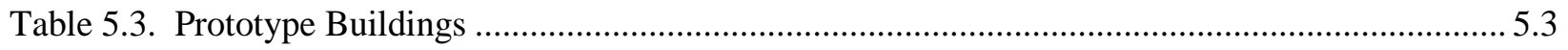

Table 5.4. HVAC Primary and Secondary Equipment ....................................................................... 5.4 


\subsection{Introduction}

The U.S. Department of Energy (DOE) ${ }^{1}$ has developed and established a methodology for evaluating the energy and economic performance of commercial energy codes. This methodology serves two primary purposes. First, as DOE participates in the codes and standards development processes, DOE will use the methodology described herein, where appropriate, to ensure that DOE's proposals are both energy efficient and cost-effective. Second, when a new edition of ANSI/ASHRAE/IES ${ }^{2}$ Standard 90.1 is published, DOE will evaluate the new standards and $\operatorname{codes}^{3}$ as a whole to estimate expected energy savings and assess cost-effectiveness, which will help inform states and local jurisdictions interested in adopting the new codes. DOE may also evaluate the cost-effectiveness of new editions of the International Energy Conservation Code (IECC). DOE's measure of cost-effectiveness balances longerterm energy savings against increases to initial costs through a life-cycle cost (LCC) perspective.

\subsection{Need for Cost-effectiveness Analysis}

Section 307 of the Energy Conservation and Production Act, as amended, directs DOE to support voluntary building energy codes by providing "assistance in determining the cost-effectiveness and the technical feasibility of the energy efficiency measures included in such standards and codes” (42 U.S.C. 6836(a)(3)) and by periodically reviewing the technical and economic basis of the voluntary building energy codes and seeking adoption of all technologically feasible and economically justified energy efficiency measures and otherwise participating in any industry process for review and modification of such codes (42 U.S.C. 6836(b)(2) and (3)).

The methodology described here supports DOE in fulfilling its charge to evaluate energy codes and energy code proposals. Where evaluation of the cost-effectiveness of codes is required, DOE intends to follow the procedures and use the parameters presented here. In some cases, DOE may rely on extant cost-effectiveness studies directly addressing the building elements involved in a proposed change, if such can be identified. When evaluating code changes proposed by entities other than DOE, ${ }^{4} \mathrm{DOE}$ may rely on energy savings estimates, cost estimates, or cost-effectiveness analyses provided by the proponent(s) or others if DOE deems the estimates and calculations credible.

\footnotetext{
${ }^{1}$ Throughout this document, DOE is identified as the primary actor in developing and applying the discussed costeffectiveness methodology. In this activity, DOE has and will use outside resources, including the work of other parties, such as the National Laboratories, to achieve its goal of evaluating cost-effectiveness of code proposals. DOE engages in this activity through the Buildings Technology Office, and uses resources from other divisions in DOE, including the Federal Energy Management Program (FEMP) and the Energy Information Administration (EIA).

${ }^{2}$ ANSI - American National Standards Institute; ASHRAE - American Society of Heating, Refrigerating and AirConditioning Engineers; IES - Illuminating Engineering Society; IESNA - Illuminating Engineering Society of North America (IESNA rather than IES was identified with Standard 90.1 prior to 90.1-2010)

${ }^{3}$ Throughout this document, when referring to energy codes, energy standards are included, as they become adopted into code, and are evaluated for their impact as an adopted code.

${ }^{4}$ All code change proposals for ASHRAE Standard 90.1 are publicly available and are published by ASHRAE as addenda for public review so that public comments can be considered by the committee in a consensus process that follows ANSI procedures. The consensus process determines whether the code changes are approved for addition to the next published edition of Standard 90.1.
} 
Incremental first cost or cost-effectiveness information is requested by code development bodies for proposals to energy codes. For example, the International Code Council (ICC) Code Development Procedures (ICC 2014) require the following:

3.3.5.6 Cost Impact: The proponent shall indicate one of the following regarding the cost impact of the code change proposal: 1) the code change proposal will increase the cost of construction; or 2) the code change proposal will not increase the cost of construction. The proponent shall submit information which substantiates either assertion. This information will be considered by the code development committee and will be included in the bibliography of the published code change proposal. Any proposal submitted which does not include the requisite cost information shall be considered incomplete and shall not be processed.

The ASHRAE 90.1 Standing Standard Project Committee (SSPC) discusses cost-effectiveness analysis related to the ANSI consensus process on pages 1 and 4 of its recent work plan: ${ }^{5}$

The main goal and primary responsibility is to publish a consensus standard in mandatory language: That sets practical, technically feasible, and cost effective minimum energy efficiency requirements for commercial buildings, except for low-rise residential buildings, on a consistent time schedule. [Emphasis added]

...Thus, neither ASHRAE nor ANSI has an overt requirement for economic analysis, nor for any other analysis for that matter, except that the SSPC must reach "consensus" before a new standard will be approved by ANSI.

That said, the Committee has often used economic analysis in its decision-making process and it continues to believe that economics play an important role in establishing the requirements for a minimum national building energy efficiency standard. Sometimes the Committee may desire a rigorous and detailed level of economic analysis, while at other times intuitive professional judgment as to the economic impact of a proposed new measure - without rigorous analysis—may be sufficient.

Thus, ICC requires cost, but not cost-effectiveness information, although such analysis often helps to advance a proposal that increases the cost of construction. ASHRAE SSPC 90.1 sees benefit in costeffectiveness analysis, although it is not always seen as necessary in the consensus process. In both cases, cost-effectiveness, where used during the code development process, is applied to individual code change proposals and not codes as a whole. Many states ${ }^{6}$ require or encourage cost-effectiveness analysis of the energy code in adoption proceedings to demonstrate that overall the code has financial benefit to the group of building users as a whole.

\footnotetext{
${ }^{5}$ Work plan presented and approved at ASHRAE SSPC 90.1 meeting in June 2014, Seattle, New York State Energy Conservation Construction Code Act WA.

${ }^{6}$ As an example, section 11-101 of the New York State Energy Conservation Construction Code Act requires "such code mandate that economically reasonable energy conservation techniques be used" and cost-effectiveness analysis of energy codes is used in their adoption process. Available at: http://public.leginfo.state.ny.us/LAWSSEAF.cgi?QUERYTYPE=LAWS+\&QUERYDATA=\$\$ENG11101\$\$@TXENG011-101+\&LIST=LAW+\&BROWSER=BROWSER+\&TOKEN=01053978+\&TARGET=VIEW.
} 


\subsection{Evaluating Cost-effectiveness}

Evaluating cost-effectiveness requires three primary steps: 1) evaluating the energy and energy cost savings of code changes, 2) evaluating the incremental and replacement costs related to the changes, and 3) determining the cost-effectiveness of energy code changes based on those costs and savings over time. The DOE methodology estimates the energy impact by simulating the effects of the code change(s) on typical new commercial buildings, assuming both old and new code provisions are implemented fully and correctly. The methodology does not estimate rates of code adoption or compliance. Cost-effectiveness is defined primarily in terms of LCC evaluation, although the DOE methodology includes several metrics intended to assist states considering adoption of new codes.

DOE intends to use the methodology described in this document to address DOE's legislative direction related to building energy codes. DOE also intends to use this methodology to inform its participation in the update processes of ASHRAE Standard 90.1 and the IECC, both in developing codechange proposals and in assessing the proposals of others when necessary. DOE further intends to use this methodology in comparing the cost-effectiveness of new code editions to prior editions or existing state energy efficiency codes.

The focus of this document is commercial buildings, which DOE defines in a manner consistent with both Standard 90.1 and the IECC_-buildings except one- and two-family dwellings, townhouses, and low-rise (three stories or less above grade) multifamily residential buildings.

This document is arranged into four primary parts covering the following:

1. Estimating the Energy and Energy Cost Savings of Code Changes-by simulating changes to representative building types. DOE defines commercial prototype buildings, establishes typical construction and operating assumptions, and identifies climate locations to be used in estimating impacts in all climate zones and all states. The building prototypes cover a range of the most typical commercial buildings and include a variety of building system types (e.g., heating and cooling equipment) to facilitate appropriate accounting for the energy use of different commercial occupancies.

2. Estimating the Incremental Cost of Code Changes - by comparing the first cost of baseline buildings to the first cost of buildings with the code implemented. Incremental replacement and maintenance costs are also accounted for. A combination of methods is used to arrive at a national incremental cost, and then adjustment factors are applied to arrive at incremental costs appropriate for states.

3. Estimating the Cost-effectiveness of Code Changes-by comparing energy cost savings to increases in the first cost of the buildings. The methodology defines four metrics — net present value (NPV) of savings, savings-to-investment ratio (SIR), scalar ratio, and simple payback period-that may be calculated. It also establishes sources for the economic parameters to be used in estimating those metrics and identifies sources of energy-efficiency measure costs.

4. Aggregating Energy and Economic Results—across building types and climate locations. The methodology establishes sources for weighting factors to be used in aggregating location- and building-type-specific results to state, national, climate zone, or other domain results. 


\subsection{Estimating the Energy and Energy Cost Savings of Code Changes}

The first step in assessing the impact of a code change or a new code is estimating the energy and energy cost savings of the associated changes. DOE will usually employ computer simulation analysis to estimate the energy impact of a code change. (Situations in which other analytical approaches might be preferred are discussed later.) Where credible energy savings estimates are not available, DOE intends to conduct analysis using an appropriate building energy estimation tool. In most cases, DOE intends to use the EnergyPlus ${ }^{\mathrm{TM}}$ (EnergyPlus 2011) software as the primary tool for its analyses. If necessary to more accurately capture the relevant impacts of a particular code change, DOE may supplement EnergyPlus with other software tools, research studies, or performance databases. Such code changes will be addressed case by case.

Code changes affecting a particular climate zone will be simulated in a weather location representative of that zone. Where a code change affects multiple climate zones, DOE intends to produce an aggregate (national or state) energy impact estimate based on simulation results from weather locations representative of each zone, weighted to account for estimated new commercial construction by zone and the fraction of specific building types that will be affected by the code change. Code changes affecting a particular climate zone will be simulated in representative weather locations. DOE's methodology includes weighting factors based on recent new building construction data to allow the individual location results to be aggregated to climate-zone and national averages as needed. These methodologies, weighting factors, and aggregation approaches are described in Section 5.0.

\subsection{Building Energy Use Simulation}

The energy performance of most energy-efficiency measures in the scope of building energy codes can be estimated by computer simulation. In estimating the energy performance of pre- and post-revision codes, two building cases will be analyzed: 1) a building that complies with the pre-revision code and 2) an otherwise identical building that complies with the revised code under analysis. These two building cases will be simulated in a variety of locations to estimate the overall (national average) energy impact of the new code or code proposal. The inputs used in those simulations are discussed in the following sections.

\subsubsection{Energy Simulation Tool}

DOE intends to use a whole building simulation tool to calculate annual energy consumption for relevant end uses. For most situations, the EnergyPlus software, developed by DOE, will be the tool of choice. EnergyPlus provides for detailed time-step (hourly or shorter time steps are typical) simulation of a building's energy consumption throughout a full year, based on typical weather data for a given location. It covers most aspects of building systems impacting energy use in commercial buildings: envelopes; heating, ventilating, and air-conditioning (HVAC) equipment and systems; water heating equipment and systems; lighting systems; and plug and process loads. Depending on how building energy codes evolve, it may be necessary to identify additional tools to estimate the impacts of some changes. For example, inputs to EnergyPlus are often established with survey data, separate engineering calculations, or ancillary analysis programs, as some systems are not directly covered within EnergyPlus 
(e.g., elevator operation, swimming pools, and two-dimensional heat transfer through assemblies of building materials).

DOE recognizes there are other tools that can produce credible energy estimates. DOE intends to use EnergyPlus as its primary tool because it includes advanced simulation capabilities, is under active development, is recognized as one of the leading simulation tools, and has the potential to include capabilities either unavailable or less sophisticated in other accepted simulation tools. EnergyPlus has capabilities for detailed simulation of complex HVAC systems, advanced capabilities for simulating interaction between primary and secondary HVAC systems, and the potential for analyzing detailed control strategies.

\subsubsection{Building Prototypes}

Separate simulations are typically conducted for multiple commercial building prototypes. The prototypes used in the simulations are intended to represent a cross section of common commercial building types covering $80 \%$ of new commercial construction. DOE developed 16 prototype building models, which were reviewed extensively by building industry experts on ASHRAE SSPC 90.1 during development and assessment of multiple editions of ASHRAE Standard 90.1. These prototype models, their detailed characteristics, and their development are published on DOE's Building Energy Codes Program (BECP) web site. ${ }^{1}$ A detailed description of the prototypes can also be found in a technical report published by Pacific Northwest National Laboratory (PNNL), Energy and Cost Savings Analysis of ASHRAE Standard 90.1-2010 (Thornton et al. 2011). The prototype models are further described in detail in the quantitative determination of the energy savings of Standard 20.1-2013 (Halverson et al. 2014). Table 2.1 shows the general characteristics DOE intends to use in analyzing the prototypes. Note that any of the prototype characteristics may be modified if a code change impacts it or such modification adds accuracy to the energy savings estimate for particular code changes.

DOE may select a subset of these prototype buildings and simulate them in representative climate locations for the cost-effectiveness analysis to represent most of the energy and cost impacts of the code changes in a particular code or proposal analysis. This approach is based on the fact that not all code requirements will apply to a set of standardized prototypes. The overall savings of a code edition will be well characterized if the preponderance of code measures and climate zones are directly modeled. The selection approach is discussed further in Section 5.1.

\footnotetext{
${ }^{1}$ See www.energycodes.gov/development/commercial/90.1_models.
} 
Table 2.1. Commercial Prototype Building Basic Characteristics

\begin{tabular}{|l|c|c|c|c|c|}
\hline \multicolumn{1}{|c|}{ Building Prototype } & $\begin{array}{c}\text { Floor Area } \\
\mathbf{f t}^{2} \mathbf{)}\end{array}$ & $\begin{array}{c}\text { Number of } \\
\text { Floors }\end{array}$ & Aspect Ratio & $\begin{array}{c}\text { Window-to- } \\
\text { Wall Ratio } \\
\text { (WWR) }\end{array}$ & $\begin{array}{c}\text { Floor-to- } \\
\text { Floor Height } \\
\text { (ft) }\end{array}$ \\
\hline Small Office & 5,500 & 1 & 1.5 & $15 \%$ & 10 \\
\hline Medium Office & 53,630 & 3 & 1.5 & $33 \%$ & 13 \\
\hline Large Office & 498,640 & $12^{*}$ & 1.5 & $40 \%$ & 13 \\
\hline Standalone Retail & 24,690 & 1 & 1.28 & $7 \%$ & 20 \\
\hline Strip Mall & 22,500 & 1 & 4 & $11 \%$ & 17 \\
\hline Primary School & 73,970 & 1 & N/A & $35 \%$ & 13 \\
\hline Secondary School & 210,910 & 2 & N/A & $33 \%$ & 13 \\
\hline Outpatient Healthcare & 40,950 & 3 & N/A & $20 \%$ & 10 \\
\hline Hospital & 241,410 & $5 *$ & 1.33 & $16 \%$ & 14 \\
\hline Small Hotel & 43,210 & 4 & 3 & $11 \%$ & $9,11^{\ddagger}$ \\
\hline Large Hotel & 122,120 & $6 *$ & $5.1,3.8 * *$ & $27 \%$ & $10,13^{\ddagger}$ \\
\hline Warehouse & 52,050 & 1 & 2.2 & $0.71 \%{ }^{\dagger}$ & 28 \\
\hline Quick-Service Restaurant & 2,500 & 1 & 1 & $14 \%$ & 10 \\
\hline Full-Service Restaurant & 5,500 & 1 & 1 & $18 \%$ & 10 \\
\hline Mid-Rise Apartment & 33,740 & 4 & 2.75 & $15 \%$ & 10 \\
\hline High-Rise Apartment & 84,360 & 10 & 2.75 & $15 \%$ & 10 \\
\hline
\end{tabular}

* These buildings also include a basement, which is not included in the number of floors.

** The large hotel basement aspect ratio is 3.8:1; all other floors have an aspect ratio of 5.1:1.

† For the warehouse, $0.71 \%$ is the overall WWR. The warehouse area has no windows; the WWR for the small office in the warehouse is $12 \%$.

$\ddagger$ The second number is the height of the first floor only.

\subsubsection{Default Inputs}

Input values for building components that do not differ between the two subject codes will be set to either 1) match a shared code requirement if one exists, 2) match standard reference design specifications from the code's performance path if the component has such specifications, or 3) match best estimates of typical practice otherwise. Examples of these items are 1) wall insulation R-values that are the same in both code editions, 2) the heating system type required for performance analysis, and 3) typical internal equipment (plug) loads based on surveys or load calculation handbooks, respectively. Because such component inputs are used in both pre- and post-revision simulations, their specific values are considered neutral and are of secondary importance, so it is important only that they be reasonably typical of the construction types being evaluated. 


\subsubsection{Provisions Requiring Special Consideration}

Some building components or energy conservation measures do not lend themselves to straightforward pre- and post-change simulation of energy consumption. For example, the use of hourly simulation is of dubious value in assessing the energy impact of service water heat piping insulation. Rather than including an exact piping heat loss model in the building simulation, typical expected losses may be separately calculated and entered as loads into the simulation model.

Another situation requiring special consideration involves analysis of new or innovative equipment that cannot be implemented directly in the energy simulation software. One example is a heat recovery device for service water heating that uses heat rejected from the chiller. Analysis of such a proposal can be effectively performed by analyzing the load outputs from EnergyPlus in a separate tabular analysis using standard engineering formulas for the impact of heat recovery on the energy use of the building. Another example of post processing is analysis of water-side economizers for Addendum $d u$ to ASHRAE Standard 90.1-2013 using hourly data extracted from EnergyPlus models (Hart et al. 2014a).

\subsection{Weather Locations}

Simulations (and other analyses as appropriate) will usually be conducted in one representative weather location per selected climate zone in the code, including a separate location for each moisture regime. ${ }^{2}$ Table 2.2 shows the climate locations typically used for a national savings analysis, each of which is represented by a Typical Meteorological Year (TMY3) ${ }^{3}$ weather data file. The locations shown in Table 2.2 for analysis through Standard 90.1-2013 were selected to be reasonably representative of their respective climate zones by Briggs et al. (2003). ASHRAE SSPC 90.1 has recently updated the representative cities to adopt changes made in ASHRAE Standard 169-2013, Climatic Data for Building Design Standards, and to provide a better match for actual average climate in each climate zone. DOE may use these updated representative locations (also shown in Table 2.2) for analysis starting with Standard 90.1-2016 and the 2018 IECC. There are several approaches for climate zone selection:

- For a national level energy saving analysis, up to 16 climate locations are used, selected from those shown in Table 2.2.

- For a national level cost-effectiveness analysis, DOE may select a subset of the climate zones to represent most of the energy and cost impacts of the code changes in a particular code or proposal analysis. The selection approach is discussed further in Section 5.1.

- For a state level code cost-effectiveness analysis, alternate cities located in each climate zone for the state are selected. A TMY3 weather station with robust data is selected within the state where possible, or adjacent to the state being analyzed if better data is in the adjacent city.

- For measures or code changes that impact primarily building envelope or are not impacted by humidity conditions, the cities representing the thermal climate zones may be used, with the results applying to the climate zones that share the same thermal climate zone numbers, regardless of moisture regime.

\footnotetext{
${ }^{2}$ Moisture regimes reflect the average humidity in a climate zone. As seen in Table 2.2, moisture regime A represents higher humidity (moist) than B (dry), while marine (C) zones have some moisture, but also have more moderate temperature ranges.

${ }^{3}$ See http://rredc.nrel.gov/solar/old_data/nsrdb/1991-2005/tmy3/.
} 
- Some analyses are conducted only for the adjoining climate zones where requirements are proposed to change. For example, increased exterior duct insulation in climate zone 5 and colder only requires an analysis in thermal climate zones 4 and 5 where the analysis shows the extra insulation is not costeffective in climate zone 4 , but is cost-effective in climate zone 5 . Because a logical argument can be made that colder climate zones will result in more heat loss, the extra insulation can be presumed to be cost-effective in climate zones 6 through 8 .

Table 2.2. Climate Locations Used in Energy Simulations

\begin{tabular}{|c|c|c|c|c|c|}
\hline \multirow[b]{3}{*}{$\begin{array}{c}\text { Climate } \\
\text { Zone* }\end{array}$} & \multirow[b]{3}{*}{$\begin{array}{l}\text { Moisture } \\
\text { Regime }\end{array}$} & \multicolumn{4}{|c|}{ Representative Locations for 90.1 National Analyses } \\
\hline & & \multicolumn{2}{|c|}{$\begin{array}{c}\text { Analysis Before and Including 90.1-2013 } \\
\text { and } 2015 \text { IECC }\end{array}$} & \multicolumn{2}{|c|}{$\begin{array}{l}\text { Analysis Starting with 90.1-2016 and } \\
2018 \text { IECC }\end{array}$} \\
\hline & & City, State & $\begin{array}{c}\text { Thermal } \\
\text { Climate Zone }\end{array}$ & City, State & $\begin{array}{c}\text { Thermal } \\
\text { Climate Zone }\end{array}$ \\
\hline $1 \mathrm{~A}$ & Moist & Miami, FL & 1 & Honolulu, HI & 1 \\
\hline $2 \mathrm{~A}$ & Moist & Houston, TX & 2 & Tampa, FL & 2 \\
\hline 2B & Dry & Phoenix, AZ & N/A & Tucson, AZ & N/A \\
\hline $3 \mathrm{~A}$ & Moist & Memphis, TN & N/A & Atlanta, GA & 3 \\
\hline 3B & Dry & El Paso, TX & 3 & El Paso, TX & N/A \\
\hline $3 \mathrm{C}$ & Marine & San Francisco, CA & N/A & San Diego, CA & N/A \\
\hline $4 \mathrm{~A}$ & Moist & Baltimore, MD & N/A & New York, NY & 4 \\
\hline $4 \mathrm{~B}$ & Dry & Albuquerque, NM & 4 & Albuquerque, NM & N/A \\
\hline $4 \mathrm{C}$ & Marine & Salem, OR & N/A & Seattle, WA & N/A \\
\hline $5 \mathrm{~A}$ & Moist & Chicago, IL & 5 & Buffalo, NY & 5 \\
\hline $5 B$ & Dry & Boise, ID & N/A & Denver, CO & N/A \\
\hline $5 \mathrm{C}$ & Marine & $\mathrm{n} / \mathrm{a}$ & N/A & Port Angeles, WA & N/A \\
\hline $6 \mathrm{~A}$ & Moist & Burlington, VT & 6 & Rochester, MN & 6 \\
\hline $6 \mathrm{~B}$ & Dry & Helena, MT & N/A & Great Falls, MT & $\mathrm{N} / \mathrm{A}$ \\
\hline 7 & N/A & Duluth, MN & 7 & International Falls, MN & 7 \\
\hline 8 & N/A & Fairbanks, AK & 8 & Fairbanks, AK & 8 \\
\hline
\end{tabular}

* Climate zones outside the United States are not shown.

\subsection{Energy Cost Savings}

Annual energy costs are a necessary part of the cost-effectiveness analysis. They are based on the energy consumption multiplied by average energy prices. For the national Standard 90.1 analysis, DOE will use the same energy prices as approved by ASHRAE SSPC 90.1 for standard development —energy prices that were based on DOE Energy Information Administration (EIA) data. Using the same prices that were used for development of a particular edition of Standard 90.1 provides a consistent approach and applies a similar cost-effectiveness threshold to the entire standard that was used for individual proposals as the standard was developed. The ASHRAE 90.1 Scalar Method identifies a fossil fuel rate ${ }^{4}$ that is primarily applied to heating energy use, with some application to service water heating. DOE may apply this mixed fuel approach to state cost-effectiveness analysis.

\footnotetext{
${ }^{4}$ The ASHRAE 90.1 Scalar Method fossil fuel rate is a blended heating rate and includes proportional costs for natural gas, propane, heating oil, and electric heat relative to national heating fuel use share. Heating energy use in the prototypes for fossil fuel equipment is calculated in therms based on natural gas equipment, but in practice, similar equipment may be operated on propane, or boilers that are modeled as natural gas may use oil in some regions.
} 
In any event, prices used for cost-effectiveness energy analyses are derived from the DOE EIA data (EIA 2012, 2014). DOE intends to use the most recently available national or state annual average commercial energy prices from the EIA. Annual average prices are used to avoid selecting a short-term price that is subject to seasonal fluctuations. If energy prices from the most recent year(s) are unusually high or low, DOE may use a longer-term average of energy prices, such as the average from the past 3 years and projections for the next 2 years. ${ }^{5}$ For individual state analysis, DOE intends to use state annual average commercial energy prices from EIA. The energy prices used in a specific analysis along with their source will be declared and documented in that analysis.

\footnotetext{
${ }^{5}$ EIA energy projections are available from either the Short-Term Energy Outlook or Annual Energy Outlook
} 


\subsection{Estimating the Incremental Costs of Code Changes}

The second step in assessing the cost-effectiveness of a proposed code change or a newly revised code is estimating the first cost of the changed provision(s). The first cost of a code change refers to the marginal cost of implementing one or more changed code provisions. For DOE's analyses, first cost refers to the retail cost (the total cost to a building developer) prior to amortizing the cost over multiple years through financing, and includes the full price paid by the building developer, including materials, sales taxes, labor, overhead, and profit. First cost excludes maintenance and other ongoing costs associated with the new code provision(s). Where regular maintenance costs are expected to be significantly different as a result of code requirements, they are estimated and converted to an annual maintenance cost, then accounted for separately on an annualized basis in the LCC calculation. There are also replacement costs estimated when individual component life is shorter than the economic study period.

DOE recognizes that estimating the first cost of a code change can be challenging, and will attempt to identify credible cost estimates from multiple sources when possible. Judgment is often required to determine an appropriate cost for energy code analysis when multiple credible sources of construction cost data yield a range of first costs. Cost data will be obtained from existing sources, including cost estimating publications such as RS Means cost estimating handbooks ${ }^{1}$; industry sources (often through web sites); and other resources including journal articles, research, and case studies. DOE may also subcontract with engineering or architectural professionals to provide specialized expertise and complete cost estimates for energy efficiency measures or representative building systems. DOE will use all of these resources to determine the most appropriate construction cost parameters based on factors including the applicability and thoroughness of the data source.

\subsection{Cost Estimating Approach}

The first step in developing the incremental cost estimates is to define the items to be estimated, such as specific pieces of equipment and their installation. The second step begins by defining the types of costs to be collected. Cost estimates cover incremental costs for material, labor, construction equipment, commissioning, maintenance, and overhead and profit. These costs are estimated both for initial construction and for replacing equipment or components at the end of their useful life during the study period. The third step is to compile the unit and assembly costs needed for the cost estimates. These costs are derived from multiple sources:

- Cost estimating consulting firms; mechanical, electrical, and plumbing (MEP) consulting engineering firms; or specialized consultants (such as daylighting) may be retained to develop general cost estimates applicable to code changes in the prototypes.

- Cost estimates for new work and later replacements are developed to approximate what a general contractor typically submits to the developer or owner and include subcontractor and contractor costs and markups.

\footnotetext{
${ }^{1}$ RS Means cost estimating handbooks are available at www.rsmeans.com/.
} 
- Maintenance costs are intended to reflect what a maintenance firm would charge. Once initial costs are developed, a technical review is often conducted by members of the ASHRAE SSPC 90.1 and PNNL internal sources.

\subsection{Sources of Cost Estimates}

Table 3.1 describes typical sources of cost estimates by category. This table is an example based on the national cost-effectiveness analysis of Standard 90.1-2013 (Hart et al. 2014b), and is typical of sources of costs that will be used in completing cost-effectiveness analyses of codes and efficiency standards for commercial buildings. In this example, RS Means refers to any of the appropriate RS Means cost estimating handbooks.

Table 3.1. Example Sources of Cost Estimates by Cost Category

\begin{tabular}{|c|c|}
\hline Cost Category & Typical Sources \\
\hline $\begin{array}{l}\text { HVAC } \\
\text { Motors included in this category }\end{array}$ & $\begin{array}{l}\text { Cost estimator and PNNL staff used quotes from suppliers and } \\
\text { manufacturers, online sources, and their own experience.* }\end{array}$ \\
\hline $\begin{array}{l}\text { HVAC } \\
\text { Ductwork, piping, selected controls } \\
\text { items }\end{array}$ & $\begin{array}{l}\text { MEP consulting engineers provided ductwork and plumbing costs based on } \\
\text { one-line diagrams they created as well as the model outputs, including } \\
\text { system airflows, capacity, and other factors, and provided detailed costs by } \\
\text { duct and piping components using RS Means } 2012 \text {. The MEP consulting } \\
\text { engineers also provided costs for several control items.* }\end{array}$ \\
\hline $\begin{array}{l}\text { HVAC } \\
\text { Selected items }\end{array}$ & $\begin{array}{l}\text { PNNL used internal expertise and experience supplemented with online } \\
\text { sources.* }\end{array}$ \\
\hline $\begin{array}{l}\text { Lighting } \\
\text { Interior lighting power allowance and } \\
\text { occupancy sensors }\end{array}$ & $\begin{array}{l}\text { PNNL staff with input from ASHRAE } 90.1 \text { Lighting Subcommittee. } \\
\text { Product catalogs were used for consistency with some other online sources } \\
\text { where needed. }\end{array}$ \\
\hline $\begin{array}{l}\text { Lighting } \\
\text { Daylighting }\end{array}$ & PNNL staff and daylighting consulting firm. \\
\hline $\begin{array}{l}\text { Envelope } \\
\text { Opaque insulation and fenestration }\end{array}$ & Costs dataset developed by professional cost estimator.* \\
\hline Commissioning & $\begin{array}{l}\text { Cost estimator, RS Means 2014, MEP consulting engineers, and PNNL } \\
\text { staff expertise. }\end{array}$ \\
\hline Labor & RS Means 2014 and the MEP consulting engineers for commissioning rate. \\
\hline Replacement life & $\begin{array}{l}\text { Lighting equipment including lamps and ballasts from product catalogs. } \\
\text { Mechanical from ASHRAE } 90.1 \text { Mechanical Subcommittee protocol for } \\
\text { cost analysis. }\end{array}$ \\
\hline Maintenance & Originator of the other costs for the affected items, or PNNL staff expertise. \\
\hline
\end{tabular}

\subsubsection{Approach to Cost Data Collection}

For code changes that impact many system or construction assembly elements of a building, DOE consults multiple national construction cost estimation publications published by RS Means, which provide a wide variety of construction cost data. This is appropriate for many code changes that impact 
the construction of commercial buildings (e.g., increasing insulation thickness on piping) where the efficiency change can be tied to incremental changes in material thickness or items clearly identified in the estimating guides. RS Means cost handbooks do not always identify the efficiency levels of products and may not have both standard and high-efficiency options. They do not, for example, have detailed costs on improved duct sealing or building envelope sealing, and the costs for fenestration products (windows, doors, and skylights) are focused on aesthetic features rather than energy efficiency characteristics such as solar heat gain coefficient or low-e coatings.

When a code change impacts only the materials used in a building, without impacting labor, cost data can often be obtained from national suppliers. These sources can have the advantage of providing recent costs, and the costs can be localized if a state or local analysis is needed. However, these sources often do not provide all the specific energy efficiency measure improvements that are typically needed for code improvement analyses.

As needed, DOE conducts literature searches of specialized building science research publications that assess the costs of new or esoteric efficiency measures that are not covered in other data sources. Examples include energy efficiency case studies, surveys of demonstration projects, utility or regional energy economic potential savings studies, and journal articles.

\subsubsection{Economies of Scale and Market Transformation Effects}

Construction costs often show substantial differences between regions, sometimes based primarily on local preferences and the associated economies of scale. Because new code changes may require building construction with new and potentially unfamiliar techniques in some locations, initial local cost estimates may overstate the long-term costs of implementing the change. For example, economizer fault diagnostics or LED parking lot lighting may be reasonably priced in California, where the technology has been required by code for a period of time. In southeastern states, the price for the same technology may be high, due to contractor unfamiliarity. Similar issues may arise where manufacturers produce large quantities of a product that just meet a current energy code requirement, giving that product a relatively low price in the market. Should the code requirement increase, it is likely that manufacturers will increase production of a new conforming product, lowering its price relative to the current premium for what is now a high efficiency product.

DOE intends to evaluate new code changes case by case to determine whether it is appropriate to adjust current costs for anticipated market transformation after a new code takes effect. DOE intends to evaluate specific new or proposed code provisions to determine whether and how prices might be expected to follow an experience curve with the passage of time. It is noted that site-built construction may involve several types of efficiency improvements. The real cost of code changes requiring new technologies may drop in the future as manufacturers learn to produce them more efficiently. The longterm cost of code changes that involve new techniques may likewise drop as contractors learn to implement them in the field more efficiently and with less labor. Finally, code changes that simply require more of a currently used technology or technique may have relatively stable real costs, with prices generally following inflation over time. 


\subsubsection{Addressing Code Changes with Multiple Approaches to Compliance}

One challenge of estimating the costs of energy code changes is selecting an appropriate characterization of new code requirements. A requirement for lower fan horsepower, for example, might be met with a more efficient fan, high surface area filters, better belts, a premium efficiency motor, more but smaller fan units, larger ductwork, or some combination of these options. Each approach will have different costs and may be subject to differing constraints depending on the situation. Some approaches, for example, may be inappropriate in some building types, but not others. Some approaches may open the possibility for new and less expensive construction approaches. Overall, DOE intends to apply two principles in reviewing options in the code:

- A single option will be selected for analysis that is expected to be the least-cost method of compliance that is considered to represent typical construction.

- If a requirement includes multiple options, and one analyzed option that is widely applicable is found to be cost-effective, the requirement will be deemed cost-effective. It is not necessary to demonstrate the cost-effectiveness of all options. This is because there is a cost-effective path through the code, and if a higher cost option is chosen, that is the developer or designer's choice.

It is difficult for DOE to anticipate either the types of code changes that will emerge in future building energy codes or the manner in which developers will choose to meet the new requirements; however, DOE intends to evaluate changes case by case and seek the least-cost way to achieve compliance unless that approach is deemed inappropriate in a large percentage of situations. For code changes that touch on techniques with which there is recent research experience (e.g., through DOE's Federal Energy Management Program (FEMP) ${ }^{2}$ and Building Technologies Office ${ }^{3}$ ), DOE will consult the relevant publications or researchers for advice on appropriate construction assumptions.

DOE anticipates that some new code provisions may have significantly different first costs depending on unrelated aesthetic choices or exceptions and flexibility options in the code. For example, a requirement for window shading could be met with interior blinds, electrochromatic windows, static exterior shading devices, or an active tracking exterior shading system. In addition, optional trade-offs may be included in the code that guarantee minimum energy performance but are not necessarily evaluated for cost-effectiveness. For example, a maximum window-to-wall ratio may be established as a baseline, but a predetermined trade-off may allow the building design to exceed that ratio if an energy recovery device or other energy saving options are included. Because the additional windows and energy saving options are optional, it is not necessary to establish the cost-effectiveness of the alternative design combination.

Finally, some new code provisions may come with no specific construction changes at all, but rather be expressed purely as a performance requirement. It is also conceivable that a code could be expressed simply as energy use intensity, where the requirement is a limit on energy use per square foot of conditioned floor area. DOE intends to evaluate any such code changes case by case and will conduct literature research or new analyses to determine the reasonable set of construction changes that could be expected to emerge in response to such new requirements. Again, DOE intends to focus on the least-cost approach deemed to be reasonable, cost-effective, and meet the code requirement.

\footnotetext{
${ }^{2}$ See http://energy.gov/eere/femp/articles/technologies.

${ }^{3}$ See http://energy.gov/eere/buildings/improving-energy-efficiency-commercial-buildings.
} 


\subsection{Cost Parameters}

Several general parameters are typically applied to all of the cost estimates. These items include new construction material and labor cost adjustments, a replacement labor hour adjustment, replacement material and labor cost adjustments, and a project cost adjustment. The cost adjustments were developed by PNNL during the cost-effectiveness analysis of Standard 90.1-2010 and were based on cost-estimating guides and practices of cost-estimating consultants for that study (Thornton et al. 2013). DOE intends to use these parameters for future estimates — unless there are changes noted in the industry —and they are described in Table 3.2 .

Table 3.2. Cost Estimate Adjustment Parameters

\begin{tabular}{|c|c|c|}
\hline Cost Items & Value* & Description** \\
\hline $\begin{array}{l}\text { New construction labor cost } \\
\text { adjustment }\end{array}$ & $52.6 \%$ & $\begin{array}{l}\text { Labor costs used are base wages with fringe benefits. Added to this is } \\
19 \%: 16 \% \text { for payroll, taxes, and insurance including worker's } \\
\text { compensation, Federal Insurance Contributions Act, unemployment } \\
\text { compensation, and contractor's liability, and } 3 \% \text { for small tools. The } \\
\text { labor cost plus } 19 \% \text { is multiplied by } 25 \%: 15 \% \text { for home office } \\
\text { overhead, and } 10 \% \text { for profit. A contingency of } 2.56 \% \text { is added as an } \\
\text { allowance to cover wage increases resulting from new labor agreements. }\end{array}$ \\
\hline $\begin{array}{l}\text { New construction material } \\
\text { cost adjustment }\end{array}$ & $\begin{array}{l}15.0 \% \\
\text { to } \\
26.5 \%\end{array}$ & $\begin{array}{l}\text { Material costs are adjusted for a waste allowance set at } 10 \% \text { in most } \\
\text { cases for building envelope materials. For other materials such as HVAC } \\
\text { equipment, } 0 \% \text { waste is the basis. The material costs plus any waste } \\
\text { allowance are multiplied by the sum of } 10 \% \text { profit on materials, and sales } \\
\text { taxes. An average value for sales taxes of } 5 \% \text { is applied. }\end{array}$ \\
\hline $\begin{array}{l}\text { Replacement - additional } \\
\text { labor allowance }\end{array}$ & $65.0 \%$ & $\begin{array}{l}\text { Added labor hours for replacement to cover demolition, protection, } \\
\text { logistics, cleanup, and lost productivity relative to new construction. } \\
\text { Added prior to calculating replacement labor cost adjustment. }\end{array}$ \\
\hline $\begin{array}{l}\text { Replacement labor cost } \\
\text { adjustment }\end{array}$ & $62.3 \%$ & $\begin{array}{l}\text { The replacement labor cost adjustment is used instead of the new } \\
\text { construction labor cost adjustment for replacement costs. The adjustment } \\
\text { is the same except for subcontractor (home office) overhead, which is } \\
23 \% \text { instead of } 15 \% \text { to support small repair and replacement jobs. }\end{array}$ \\
\hline $\begin{array}{l}\text { Replacement material cost } \\
\text { adjustment }\end{array}$ & $\begin{array}{l}26.5 \% \\
\text { to } \\
38.0 \%\end{array}$ & $\begin{array}{l}\text { The replacement material cost adjustment is used instead of the new } \\
\text { construction material cost adjustment for replacement costs. The } \\
\text { adjustment is for purchase of smaller lots and replacement parts. } 10 \% \text { is } \\
\text { added and then is adjusted for profit and sales taxes. }\end{array}$ \\
\hline Project cost adjustment & $28.8 \%$ & $\begin{array}{l}\text { The combined labor, material, and any incremental commissioning or } \\
\text { construction costs are added together and adjusted for subcontractor } \\
\text { general conditions and for general contractor overhead and profit. } \\
\text { Subcontractor general conditions add } 12 \% \text { and include project } \\
\text { management, job-site expenses, equipment rental, and other items. A } \\
\text { general contractor markup of } 10 \% \text { and a } 5 \% \text { contingency are added to the } \\
\text { subcontractor subtotal as an alternative to calculating detailed general } \\
\text { contractor costs (RS Means 2014). }\end{array}$ \\
\hline
\end{tabular}

* Values shown and used are rounded to first decimal place.

** Values provided by the cost estimator except where noted.

For national cost-effectiveness studies, costs are not adjusted for climate locations. The climate location results are intended to represent an entire climate subzone even though climate data for a particular city is used for simulation purposes. Costs will vary significantly between a range of urban, suburban, and rural areas within the selected climate locations, which typically cross multiple states. For state-level cost-effectiveness analysis, costs are adjusted for specific cities based on city cost index adjustments from RS Means or other sources. 


\subsection{Cost Updating for Inflation}

Cost estimates are typically developed for current national average prices. Labor costs are based on estimated hours and current crew labor rates from RS Means. In some cases, cost estimates completed for a prior code cycle are still applicable, and are adjusted for inflation rather than creating a new cost estimate or obtaining current unit prices throughout the cost estimate. Where cost estimates are updated, inflation factors specific to the equipment are used. These inflation factors are developed for each specific equipment or insulation type by comparing RS Means from the time of the estimate with the current RS Means.

\subsection{Cost Estimate Spreadsheet Workbook}

To provide a transparent view of the costs used in the analysis, a cost estimate spreadsheet will typically be prepared in conjunction with the cost-effectiveness report. The intent of such a cost estimate is to show the basis for costs used in the analysis, although in some cases detailed information obtained from individual manufacturers will be averaged and only the average value will be included in the documentation. For some individual proposals, a spreadsheet may not be necessary, as the costs may be cited from other documents or sources. As one example, the cost estimate spreadsheet for the analysis of Standard 90.1-2013 (Hart et al. 2014b) was organized in the following sections:

1. Introduction

2. HVAC cost estimates

3. Lighting cost estimates

a. Interior lighting power density

b. Interior lighting occupancy related controls

c. Daylighting controls

4. Envelope, power, and other cost estimates

5. Cost estimate summaries and cost-effectiveness analysis results

DOE may also provide a calculating tool that allows cost adjustments to be entered, especially for state analysis. This allows local evaluation of particular cost or other economic impacts to be adjusted in evaluating codes for use by states in the adoption process. For DOE's assessment of cost-effectiveness, the researched input values for economic and cost parameters will continue to be used. 


\subsection{Estimating the Cost-effectiveness of Code Changes}

The last step in assessing the cost-effectiveness of a proposed code change or a newly revised code is calculating the corresponding economic impacts of the changed provision(s). These impacts are measured under different economic scenarios with several economic metrics.

\subsection{Cost-effectiveness Analysis}

The intent of the DOE cost-effectiveness methodology is to determine whether code changes are economically justified from the perspective of a public policy that balances increased building costs against energy savings over time. The DOE methodology accounts for the benefits of energy-efficient building construction to building owners and tenants that accrue over 30 years. To accommodate multiple economic views, the LCC analysis is applied to multiple scenario methods: Publicly-Owned Method, Privately-Owned Method, and ASHRAE 90.1 Scalar Method. The scenarios, methodologies, and input parameters are described in this section.

Cost-effectiveness is analyzed using the incremental cost information presented in Section 3.0 and the energy cost information presented in Section 2.0. Multiple economic metrics are available, as discussed further in Section 4.2. Several of these may be presented in a particular analysis, and they are selected from the following:

- Life-cycle cost net savings (a.k.a., NPV of savings)

- Savings-to-investment ratio

- The ASHRAE 90.1 scalar ratio

- Simple payback period

\subsubsection{Economic Scenarios}

Commercial building developers and owners have different perspectives, depending primarily on whether the ownership is public or private. The building owner has a different view of the economic impact of energy purchases as a landlord than as an owner who occupies the building. In tenant situations, the energy operating costs may be paid by the tenant directly to utilities or indirectly via the building owner through a net lease. In the latter situation, the costs for energy efficiency may be paid by a building owner who does not receive energy benefits through reduced bills; however, these incremental costs can be considered to be passed through to the tenant in the lease rates. In every case, someone will pay the energy bill for the building — having savings if it is a more efficient building — and someone will pay the added cost of a more efficient building. While local rental market conditions may result in higher or lower lease rates relative to the incremental cost of efficiency improvements, a complete economic model of such variability would be quite difficult to implement. To provide a straightforward and economic equivalent analysis, the cost-effectiveness analysis will be from the point of view of a building owner who receives the benefits of energy savings. This approach puts the analysis of the costs and savings of all energy saving measures on a common footing for analysis. 
DOE evaluates energy codes and code proposals based on LCC analysis over a multi-year study period, accounting for energy savings, incremental investment for energy efficiency measures, and other economic impacts. The value of future savings and costs are discounted to a present value, with improvements deemed cost-effective when the NPV of savings (present value of savings minus present value of costs) is positive. Because the economic criteria of different commercial building owners vary, up to three scenarios may be used for cost-effective analysis:

- Scenario 1 (also referred to as the Publicly-Owned Method): LCC analysis method representing government or public ownership (without borrowing or taxes). This scenario uses a real dollar methodology and economic inputs that have been established for federal projects under FEMP as amended by the Energy Independence and Security Act of 2007 (EISA).

- Scenario 2 (also referred to as the Privately-Owned Method): LCC analysis method representing private or business ownership (includes loan and tax impacts). This scenario uses typical commercial economic inputs, with initial costs being financed, and considers tax impacts for savings, interest, and depreciation. The general methodology is identical to that used under Scenario 1, except that it is a nominal dollar analysis with the addition of consideration for income and property taxes, financing, and a private sector discount rate.

- Scenario 3 (also referred to as the ASHRAE 90.1 Scalar Method (McBride 1995)): Represents a pretax private investment point of view, and uses economic inputs established by the ASHRAE SSPC 90.1. The ASHRAE 90.1 Scalar Method uses standard life-cycle costing techniques in a similar manner to Scenarios 1 and 2, although the parameters and methodology used in the analysis are established by ASHRAE SSPC 90.1.

It is important to understand that, except for the minor adjustments noted here, DOE uses methods and parameters established by others for Scenarios 1 and 3. Scenario 1 parameters are established by federal statute (42 U.S.C. 8254). Scenario 3 parameters are established by ASHRAE SSPC 90.1 for each edition of Standard 90.1. The method and parameters used for Scenario 2 are established by DOE, although the method and parameters are developed and selected to be consistent with Scenario 1 except where typical private investment criteria support different parameters.

When selecting scenarios for a particular cost-effectiveness analysis, DOE notes that Scenarios 2 and 3 both reflect a private-ownership view. As a result, each analysis typically includes Scenario 1 to reflect a public-ownership view and the private-ownership view is reflected by either Scenario 2 or 3 . For a national analysis, the ASHRAE Scalar Method (McBride 1995) is used for the private-ownership view, as this was the method applied to individual proposals in development of the standard. The ASHRAE energy prices are typically used for the national analysis, again for consistency with the individual proposal analyses. For individual state analysis, DOE typically uses local state energy prices, and costeffectiveness is determined based on LCC using Scenario 1 and Scenario 2 economic parameters. Scenario 2 is used as the Private-Ownership Method for state analysis, since the method and parameter selection can be maintained on a consistent basis by DOE. Scenario 2 also more closely matches Scenario 1 and the cost-effectiveness method used for residential codes than does Scenario 3.

\subsubsection{Cost-effectiveness Methodology}

The primary basis of cost-effectiveness assessment is an LCC analysis. The LCC analysis perspective compares the present value of incremental costs, replacement costs, and maintenance and 
energy cost savings for each prototype building and climate location. The degree of borrowing and the impact of taxes vary considerably for different building projects, creating many possible cost scenarios. These varying costs are not included in the Scenario 1 Publicly-Owned Method LCC analysis, but are included with the Privately-Owned Method Scenario 2 analysis and the Scenario 3 SSPC 90.1 Scalar Method.

The LCC analysis approach is based on the LCC analysis method used by FEMP, ${ }^{1}$ a method required for federal projects and used by other organizations in both the public and private sectors (NIST 1995). The LCC analysis method consists of identifying costs (and revenues, if any) and the year in which they occur, and determining their value in present dollars (known as the net present value). This method uses fundamental engineering economics relationships about the time value of money. For example, money in hand today is normally worth more than money received tomorrow, which is why people pay interest on a loan and earn interest on savings. Future costs are discounted to the present based on a discount rate. The discount rate may reflect what interest rate can be earned on other conventional investments with similar risk, or in some cases, the interest rate at which money can be borrowed for projects with the same level of risk.

\subsubsection{Discounted Value}

The following calculation method can be used to account for the present value of costs or revenues:

Present Value $=$ Future Value $/(1+i)^{n}$

$i$ is the discount rate (or interest rate in some analyses)

$n$ is the number of years in the future the cost occurs

The present value of any cost that occurs at the beginning of year 1 of an analysis period is equal to that initial cost. For this analysis, initial construction costs occur at the beginning of year 1, and all subsequent costs occur at the end of the future year identified.

\subsubsection{Study Period}

The LCC analysis depends on the number of years into the future that costs and revenues are considered, known as the study period. While the FEMP method allows a 40-year ${ }^{2}$ study period (42 U.S.C. 8254(a)(1)), the DOE code analysis method uses 30 years for Scenarios 1 and 2 and 40 years for Scenario 3. Thirty years is the same study period used for the cost-effectiveness analysis of the residential energy code, conducted by DOE and PNNL (DOE 2012), and is the same period used in previous cost-effectiveness evaluations of Standard 90.1 (Thornton et al. 2013; Hart et al. 2014a). National Institute of Standards and Technology (NIST)-provided energy escalation and discount rates are also limited to 30 years. The 30-year study period is also widely used for LCC analysis in government and industry, and the Office of Management and Budget long-term study period is set at 30 years. The study period is also a balance between capturing the impact of future replacement costs, inflation, and energy escalation; the higher the uncertainty of these costs, the further into the future they are considered.

\footnotetext{
${ }^{1}$ See 10 CFR part 436, subpart A, “Methodology and Procedures for Life Cycle Cost Analyses,” Jan. 1, 2004.

2 Section 441 of EISA amended the FEMP cost-effective methodology to increase the maximum study period from 25 to 40 years (42 U.S.C. 8254(a)(1)).
} 


\subsubsection{Residual Value}

When the length of the study period does not exactly match the measure life, the residual value of equipment beyond the period of analysis is accounted for. The FEMP LCC analysis method includes a simplified approach for determining the residual value. The residual value is the proportion of the initial cost equal to the remaining years of service divided by the initial cost. For example, the residual value of a wall assembly in year 30 is (40-30)/40 or $25 \%$ of the initial cost. The residual values applied in year 30 are discounted from year 30 to a present value and included as a reduction in the total present value of cost. Three cases need to be considered for residual value:

- Where the measure life matches the study period, or an even multiple of the life matches the study period, there is no residual value. For example, electronic controls with a 15-year life in a 30-year study period include a replacement cost at year 15, and that replacement has no further value at year 30 , so the residual value is zero.

- Where the useful life of equipment or materials extends beyond the study period, there is a residual value. For code measures analyzed, the longest useful life defined is 40 years for all envelope cost items, such as wall assemblies, as recommended by the SSPC 90.1 Envelope Subcommittee. Forty years is longer than the 30-year study period used in Scenario 1 and 2 LCC analyses. A residual value of the unused life of a cost item is calculated at the last year of the study period for components with longer lives than the study period. So, for example, a measure with a 40 -year life in a 30-year study period would have a residual value of $25 \%$ of its first cost.

- Where the replacement life does not fit neatly into the study period (e.g., a chiller with a 23-year useful life), the residual value is not a salvage value, but rather a measure of the available additional years of service not yet used for the replacement. To use the chiller example with a 30-year study period, at 30 years there is a 16-year $(23+23-30)$ residual life remaining. So the residual value would be (46-30)/23, or $69.5 \%$ of the replacement cost, discounted from year 30 to present value.

\subsection{Economic Metrics}

In evaluating code change proposals and assessing new editions of commercial building energy codes, DOE intends to calculate multiple metrics selected from the following:

- Life-cycle cost net savings (a.k.a., NPV of savings)

- Savings-to-investment ratio

- The SSPC 90.1 scalar ratio

- Simple payback period

Life-cycle cost net savings is the primary metric DOE intends to use to evaluate whether a particular code change is cost-effective. Any code change that results in an LCC net savings greater than or equal to zero (i.e., monetary benefits exceed costs) will be considered cost-effective. The payback period and SIR analyses provide additional information DOE believes is helpful to other participants in code change processes and to states and jurisdictions considering adoption of new codes. These metrics are discussed further below. 


\subsubsection{Life-Cycle Cost Net Savings}

Life-cycle cost net savings is a robust cost-benefit metric that sums the costs and benefits of a code change over a specified period. Sometimes referred to as net present value analysis or engineering economics, LCC analysis is a well-known approach to assessing cost-effectiveness. Because the key feature of LCC analysis is the summing of costs and benefits over multiple years, it requires that cash flows in different years be adjusted to a common year for comparison. This is done with a discount rate that accounts for the time value of money. Like most LCC implementations, DOE's method sums cash flows in year-zero dollars, which allows the use of standard discounting formulas. Cash flows adjusted to year zero are termed present values. The procedure used for discounting is taken directly from the FEMP cost-effective methodology for federal buildings ${ }^{3}$ as described in NIST Handbook 135 (Fuller and Petersen 1995). In actual practice, these procedures have been implemented in a spreadsheet format to produce identical results, rather than using the manual worksheets included in NIST Handbook 135 or the FEMP Building Life Cycle Cost computer program. ${ }^{4}$ Formulas shown in Table 4.4 are taken from or adapted directly from formulas in NIST Handbook 135. Where situations are not covered by the FEMP cost-effective methodology, DOE will apply concepts from two ASTM International standard practices, E917 (ASTM 2010a) and E1074 (ASTM 2010b), or as outlined in the ASHRAE HVAC Applications Handbook (ASHRAE 2011). The resultant procedure is both straightforward and comprehensive and is in accord with the methodology recommended and used by NIST. ${ }^{5}$

Present values can be calculated in either nominal or real terms. In a nominal analysis, all compounding rates (discount rate, mortgage rate, energy escalation rate, etc.) include the effect of inflation, while in a real analysis inflation is removed from those rates. The two approaches are algebraically and economically equivalent, and for commercial analysis DOE intends to use a real analysis for Scenario 1. In Scenario 2, nominal discounting is applied for constant future cash flows such as loan payments and related tax deductions, while a private sector real discount rate is applied to account for inflation on items such as maintenance and replacement costs, property taxes, and energy savings. ${ }^{6}$ This approach is equivalent to a nominal analysis. Scenario 3 is a nominal analysis from a privateownership viewpoint.

LCC is defined formally as the present value of all costs and benefits summed over the period of analysis. For Scenarios 1 and 2, DOE will typically use NPV of savings as the commercial test metric, which is one of three equivalent ways to quantify LCC:

- Calculate the LCC of both options, including all costs (first, maintenance, replacement, and energy), independently and compare them. In this case, the lower LCC would be the preferable alternative, and the case representing the new code would need a lower LCC than the old code case to be considered cost-effective.

- Calculate the present value of the incremental costs and subtract the present value of the incremental benefits. The result is the LCC of the change, expressed as a cost. In this case, the net cost should be negative to justify the change.

\footnotetext{
${ }^{3}$ See 10 CFR part 436, subpart A, “Methodology and Procedures for Life Cycle Cost Analyses,” Jan. 1, 2004.

${ }^{4}$ See http://www1.eere.energy.gov/femp/information/download_blcc.html.

${ }^{5}$ For a detailed discussion of LCC and related economic evaluation procedures specifically aimed at private sector analyses, see Ruegg and Petersen 1987.

${ }^{6}$ Using a real discount rate to discount uninflated future values is equivalent to using a nominal discount rate to discount inflated future values.
} 
- Calculate the present value of the incremental benefits and subtract the present value of the incremental costs. The result is the LCC net savings or the NPV of savings, also referred to as the NPV of savings. In this case, the NPV of savings should be positive or zero to justify the change. Since a positive result represents a cost-effective outcome, this metric is preferred, and its calculation is shown in Eq. (1).

$$
\text { NPV of savings }=P V(\text { Incremental Benefits })-P V(\text { Incremental Costs })
$$

In LCC analysis, a future cash flow (positive or negative) is brought into the present by assuming a discount rate (D). The discount rate is an annually compounding rate ${ }^{7}$ by which future cash flows are discounted in value. It represents the minimum rate of return demanded of the investment in energysaving measures. It is sometimes referred to as an alternative investment rate.

\subsubsection{Savings-to-Investment Ratio}

An additional metric that may be used in Scenarios 1 and 2 is SIR, a ratio of benefits to costs, as shown in Eq. (2). The SIR of a code change must be greater than 1.0 for the change to be considered costeffective, unless costs are negative and the code change is obviously cost effective.,

$$
S I R=\frac{P V(\text { Benefits })}{P V(\text { Costs })}
$$

The calculation of SIR is further defined in the regulations for the FEMP cost-effective methodology for federal buildings. ${ }^{1}$ The SIR has the advantage of allowing comparison between two alternative items reviewed for cost-effectiveness. When a threshold of "SIR greater than 1.0" is used, the assessment of cost-effectiveness is the same as it is for the NPV of savings metric.

\subsubsection{Scalar Ratio}

The scalar ratio is used specifically for Scenario 3, the ASHRAE SSPC 90.1 Scalar Method. Using this approach, the payback is calculated as the sum of the first costs and present value of the replacement costs, divided by the difference of the energy cost savings and incremental maintenance cost. The result is compared to the scalar ratio limit that is dependent on the life of a measure. A code change is considered cost-effective if the payback is less than the limit. For the analysis of 90.1-2016 with a 40year study period, the scalar ratio limit is 21.4 for heating or fossil fuel savings, 18.2 for cooling or electric savings, or a weighted limit for mixed savings. Unlike the simple payback period, this is a true cost-effectiveness method, because the scalar ratio threshold has been developed similar to a discounted payback using cost-effectiveness methods.

\subsubsection{Simple Payback Period}

The simple payback period is a straightforward metric that includes only the costs and benefits directly related to the implementation of the energy-saving measures associated with a code change. It

\footnotetext{
${ }^{7}$ The analysis can be done for other periods of time (e.g., monthly), but for simplicity DOE uses annual periods for the subject analyses.
} 
represents the number of years required for the energy savings to pay for the cost of the measures, without regard for changes in energy prices, tax effects, measure replacements, resale values, etc. The payback period $P$, which has units of years, is defined as the marginal cost of compliance with a new code ( $C$, the "first costs" above and beyond the baseline code), divided by the annual marginal benefit from compliance ( $E S_{0}$, the energy cost savings in year 0 , less $M_{a}$, annual maintenance cost increases), as shown in Eq. (3).

$$
P=\frac{C}{E S_{0}-M_{a}}
$$

The simple payback period is a metric useful for its simplicity and ubiquity. Because it focuses on the two primary characterizations of a code change — cost and energy performance-it allows an assessment of cost-effectiveness that is easy to compare with other investment options and requires a minimum of input data. The simple payback period is used in many contexts, and may be desired by state agencies considering the adoption of new energy codes; hence, DOE will calculate the payback period when it assesses the cost-effectiveness of code changes. However, because payback period ignores many of the longer-term factors in the economic performance of an energy efficiency investment, DOE does not intend to use the payback period as a primary indicator of cost-effectiveness for its own decision-making purposes.

This method does not take into account any costs or savings after the year in which payback is reached, does not consider the time value of money, and does not take into account any replacement costs, even those that occur prior to the year in which simple payback is reached. The method also does not have a defined threshold for determining whether an alternative's payback is cost-effective. Decision makers generally set their own threshold for a maximum allowed payback. The simple payback perspective is reported for information purposes only, not as a basis for concluding that a particular code, standard, or proposal is cost-effective.

\subsubsection{Economic Metric Summary}

To provide a better understanding of the relationship of the various economic metrics, the metrics are summarized in Table 4.1. Each metric is named, with its abbreviation, and the applicable scenarios and cost-effective thresholds are provided.

Table 4.1. Economic Metrics

\begin{tabular}{|l|c|c|l|}
\hline \multicolumn{1}{|c|}{ Metric } & Abbreviation* & Used in Scenarios & Cost-effectiveness Threshold \\
\hline $\begin{array}{l}\text { Life-Cycle Cost Net Savings } \\
\text { (a.k.a. Net Present Value of Savings) }\end{array}$ & NPV & 1,2 & $\geq 0$ \\
\hline Savings-to-Investment Ratio & SIR & 1,2 & $\geq 1.0$ \\
\hline Simple Payback & SPP & $1,2,3$ & $\begin{array}{l}\text { Does not measure cost- } \\
\text { effectiveness }\end{array}$ \\
\hline Scalar Ratio** & N/A & 3 & $\begin{array}{l}\leq 21.4 \text { for 40-year life heating } \\
\leq 18.2 \text { for 40-year life cooling }\end{array}$ \\
\hline
\end{tabular}

* NPV = net present value of savings; SPP is simple payback period.

${ }^{* *}$ The scalar ratio is tested against a limit set by the measure life, fuel type, and economic parameters used for each edition of Standard 90.1. The values shown are for 90.1-2016. Heating is a blended fossil fuel rate, and cooling is for electric measures. 


\subsection{Economic Parameters and Other Inputs}

Calculating the metrics described above requires defining various economic parameters. Table 4.2 shows the primary parameters of interest and how they apply to the four metrics. There is also some variation of requirement depending on the economic scenario.

Table 4.2. Economic Parameters Required for Cost-effectiveness Metrics

\begin{tabular}{|l|c|c|c|c|}
\hline \multirow{2}{*}{\multicolumn{1}{|c|}{ Parameter }} & \multicolumn{3}{|c|}{ Parameter Needed for Metric } \\
\cline { 2 - 5 } & $\begin{array}{c}\text { Scenario 1 } \\
\text { LCC \& SIR }\end{array}$ & $\begin{array}{c}\text { Scenario 2 } \\
\text { LCC \& SIR }\end{array}$ & $\begin{array}{c}\text { Scenario 3 } \\
\text { Scalar Ratio }\end{array}$ & $\begin{array}{c}\text { Simple } \\
\text { Payback } \\
\text { Period }\end{array}$ \\
\hline $\begin{array}{l}\text { First costs, including sales tax on } \\
\text { materials }\end{array}$ & Yes & Yes & Yes & Yes \\
\hline Energy savings & Yes & Yes & Yes & Yes \\
\hline Energy prices & Yes & Yes & Yes & Yes \\
\hline Energy price escalation rates & Yes & Yes & Yes & No \\
\hline Period of analysis & Yes & Yes & Yes & No \\
\hline $\begin{array}{l}\text { Replacement costs and } \\
\text { residual value }\end{array}$ & Yes & Yes & Yes & No \\
\hline Discount rate (real and nominal) & Real & Nominal & Nominal & No \\
\hline Loan parameters (rate and term) & No & Yes & Yes & No \\
\hline Inflation rate & No & Yes & Yes & No \\
\hline Tax rates, federal and state income tax & No & Yes & Yes* & No \\
\hline Tax rate, property tax & No & Yes & No & No \\
\hline
\end{tabular}

* Income tax rates are not required for Scalar Ratio analysis of Standard 90.1-2016 proposals, as the discount rate is pre-tax.

These parameters are chosen to represent the economic impact of a typical commercial building ownership or tenant situation. DOE intends to consult appropriate sources of information to establish assumptions for each financial, economic, and energy price assumption. Whenever possible, economic assumptions will be taken from the published sources discussed below. DOE notes that most values vary across time, location, markets, institutions, circumstances, and individuals. Where multiple sources for any parameter are identified, DOE will prefer recent values from sources DOE deems best documented and most reliable.

DOE intends to update parameters for future analyses to account for changing economic conditions. The current parameters for use in analyzing proposals for Standard 90.1-2016 and the 2018 IECC are included in Appendix A. In some cases, state-level analysis of the completed edition of a code may use different economic parameters than were used for individual proposals, as individual proposals are typically analyzed at a national level, and several years earlier than the final evaluation of a code edition. The parameters used and their sources will be documented in each particular analysis. Parameters for this methodology have been published at the BECP web site ${ }^{8}$ starting with analysis for 2015 IECC in mid2012.

\footnotetext{
${ }^{8}$ See http://www.energycodes.gov/development/commercial/methodology.
} 
Table 4.3. Economic Parameters and Their Symbols

\begin{tabular}{|l|c|}
\hline \multicolumn{1}{|c|}{ Parameter } & Symbol \\
\hline Period of Analysis & $L$ \\
\hline Energy Prices & N/A \\
\hline Energy Escalation Rates & N/A \\
\hline Loan Term & $M_{L}$ \\
\hline Loan Interest Rate & $I$ \\
\hline Nominal Discount Rate & $D_{n}$ \\
\hline Real Discount Rate & $D_{r}$ \\
\hline Inflation Rate & $R_{I N F}$ \\
\hline Property Tax Rate & $R_{P}$ \\
\hline Income Tax Rate, federal & $R_{T F}$ \\
\hline Income Tax Rate, state & $R_{T S}$ \\
\hline
\end{tabular}

\subsubsection{Scenario 1: Publicly-Owned Method Parameters}

The LCC analysis requires assumptions about what the value of money today is relative to money in the future, and about how values of the cost items will change over time, such as the cost of energy and HVAC equipment. These values are determined by the analyst depending on the purpose of the analysis. In the case of the FEMP LCC analysis method, NIST periodically publishes an update of economic factors (Rushing et al. 2013).

The DOE nominal discount rate is based on long-term Treasury bond rates averaged over the 12 months prior to publication of the NIST report. The nominal rate is converted to a real rate to correspond with the constant-dollar analysis approach for this analysis. The method for calculating the real discount rate from the nominal discount rate uses the projected rate of general inflation published in the most recent Report of the President's Economic Advisors, Analytical Perspectives (referenced in the NIST 2013 and 2011 annual supplements without citation). The mandated procedure would result in a discount rate for 2011 and 2013 lower than the 3.0\% floor prescribed in 10 CFR 436. Thus, the 3.0\% floor is used as the real discount rate for FEMP analyses in 2011 and 2013. The implied long-term average rate of inflation was calculated as $-0.5 \%{ }^{9}$ (Rushing et al. 2013).

\subsubsection{Scenario 2: Privately-Owned Method Parameters}

For Scenario 2, there are seven primary cash flows that are relevant to LCC analysis of energy code changes, summarized in Table 4.4. The total cost of the code changes $(C)$ is not directly included in the analysis; rather, the incremental cost $(C)$ is accounted for as loan payments assumed to occur over the 30 year (or other) study period. Replacement costs $\left(C_{r}\right)$ for items that have shorter lives than the study period are often calculated at a higher cost than the initial installation to account for more difficulty in installation during replacement rather than new construction. The replacement costs are also incremental costs, reflecting cost increases or reductions required due to the new code. The replacement is made and the same efficiency and savings are estimated to continue. Where a measure or replacement does not have a life equal to or evenly divisible by the study period, there is a residual value, incurred at the end of the analysis period. The residual value is the cost of the code changes, multiplied by the fraction of the lifetime (i.e., value) of the code changes or replacements remaining at the end of the study period. This is

\footnotetext{
${ }^{9}$ The negative implied long-term inflation rate is not a prediction of deflation, but a result of the $3.0 \%$ floor on the discount rate, when the actual discount rate was lower. The negative inflation rate is not required in real analysis.
} 
a simplified treatment of residual value, similar to straight-line depreciation, but is meant to encapsulate an average of the remaining lifetime of all components. The replacement and residual costs are discounted using a real discount rate to account for inflation, which is equivalent to inflating the costs, then discounting them with a nominal rate. Annual maintenance costs $\left(M_{a}\right)$ are also accounted for. Property tax occurs every year, starting on year 1 , is the property tax rate $\left(R_{P}\right)$ multiplied by $C$, and is discounted with a real rate, which again is equivalent to property values increasing at the rate of inflation and then being discounted at a nominal rate. This assumes that the tax assessment of the building increases by exactly the same amount as the code-related cost increase, and that the tax assessment increases in step with inflation. The cost of property tax is the net of a federal tax $\left(R_{T F}\right)$ deduction benefit.

Energy savings occur every year, starting at year 1, and are equal to the calculated energy cost savings at year $0\left(E S_{0}\right)$, adjusted by the real escalation rates required to be used in the FEMP costeffective methodology. These escalation rates exclude inflation, so the escalated energy savings are discounted to present value using a real discount rate $\left(D_{r}\right)$, which again is equivalent to applying a combination of inflation and escalation to energy costs, to estimate their nominal future value, and then discounting with a nominal discount rate $\left(D_{n}\right)$. Discount and escalation rates for the FEMP cost-effective methodology are established annually by NIST and published in the NIST Handbook 135 Supplement (Rushing et al. 2013). Loan payments occur every year of the study period, are constant payments, and are calculated as an annual payment, as calculated using the standard equation shown in Table 4.4. 
Table 4.4. Present Value Cost and Benefit Components for Scenario 2

\begin{tabular}{|c|c|c|c|}
\hline Cost Item & Equation for Present Value & $\begin{array}{c}\text { Discount } \\
\text { Rate }\end{array}$ & $\begin{array}{l}\text { Cost or } \\
\text { Benefit }\end{array}$ \\
\hline First Cost* & $\mathrm{C}$ & N/A & N/A \\
\hline Loan Payments & $C\left(\frac{i(1+i)^{M_{L}}}{(1+i)^{M_{L}}-1}\right)\left(\frac{\left(1+D_{n}\right)^{M_{L}}-1}{D_{n}\left(1+D_{n}\right)^{M_{L}}}\right)$ & Nominal & Cost \\
\hline $\begin{array}{l}\text { Replacement Costs and Residual } \\
\text { Value }\end{array}$ & $\frac{C_{r}}{\left(1+D_{r}\right)^{Y}}$ & Real & Cost \\
\hline Maintenance Costs & $M_{a}\left(\frac{\left(1+D_{r}\right)^{L}-1}{D_{r}\left(1+D_{r}\right)^{L}}\right)$ & Real & Cost \\
\hline $\begin{array}{l}\text { Property Tax Net of Fed Income Tax } \\
\text { Benefit }\end{array}$ & $C\left(R_{P}\right)\left(\frac{\left(1+D_{r}\right)^{L}-1}{D_{r}\left(1+D_{r}\right)^{L}}\right)\left(1-R_{T F}\right)$ & Real & Cost \\
\hline $\begin{array}{l}\text { Energy Savings Net of Income Tax } \\
\text { Penalty }\end{array}$ & $\begin{array}{l}\left.\text { (1- } R_{T C}\right) \text { (Annual Energy Savings Escalated } \\
\text { with NIST rates that change over time, and } \\
\text { then discounted with real discount rate } D_{r} \text { to } \\
\text { be equivalent to applying inflation and then } \\
\text { using a nominal discount rate } D_{n} \text { ) }\end{array}$ & $\begin{array}{l}\text { Real, } \\
\text { escalated }\end{array}$ & Benefit \\
\hline Interest Tax Deduction** & $\left(1-R_{T C}\right) \sum_{Y=1} \frac{L I_{Y}}{\left(1+D_{r}\right)^{Y}}$ & Nominal & Benefit \\
\hline Depreciation Tax Deduction & $\frac{C}{39}\left(\frac{\left(1+D_{n}\right)^{39}-1}{D_{n}\left(1+D_{n}\right)^{39}}\right) R_{T C}$ & Nominal & Benefit \\
\hline
\end{tabular}

Note: Symbols for variables are listed in Table 4.3 and discussed in Section 4.3.4.

* First cost $(C)$ is not directly used in the Scenario 2 LCC or SIR. As previously discussed, Scenario 2 uses a financed approach, and the present value of the loan payments is treated as a cost in the LCC or SIR.

** Loan interest paid in a given year $\left(L I_{Y}\right)$ is simply the mortgage interest rate multiplied by the loan balance. The loan balance is calculated as the present value in year $Y$ of the remaining stream of loan payments, discounted at the mortgage interest rate.

For Scenario 2, tax deductions for loan interest payments begin in year 1 and continue through the end of the 30-year analysis period. A depreciation tax benefit is calculated based on a 39-year straightline depreciation applicable to commercial buildings (IRS 2012a). This depreciation benefit is calculated for the full 39 years that it is available for current and future property owners. While the depreciation extends beyond the study period, calculating this value for the full 39-year straight-line depreciation term is considered the most straightforward approach to capturing the residual value of this benefit, as these deductions will continue beyond the study period with a high level of certainty. The income tax deductions are calculated at the combined effective state and federal income tax rate $\left(R_{T C}\right)$ multiplied by the sum of loan interest payments and depreciation taken each year. The combined $\left(R_{T C}\right)$ effective state $\left(R_{T S}\right)$ and federal $\left(R_{T F}\right)$ income tax rate is based on state taxes being deductible from federal taxes, as shown in Eq. (4).

$$
R_{T C}=R_{T F}+R_{T S}\left(1-R_{T F}\right)
$$




\subsubsection{Scenario 3: ASHRAE 90.1 Scalar Method Parameters}

The SSPC 90.1 does not consider cost-effectiveness of the entire set of changes for an update to the whole Standard 90.1. However, cost-effectiveness is often considered when evaluating a specific addendum to Standard 90.1. The Scalar Method was developed by SSPC 90.1 to evaluate the costeffectiveness of proposed changes (McBride 1995). The Scalar Method is an alternative LCC approach for individual energy efficiency changes with a defined useful life, taking into account first costs, annual energy cost savings, annual maintenance, taxes, inflation, energy escalation, and financing impacts. The Scalar Method allows a discounted payback threshold (scalar ratio limit) to be calculated based on the measure life. Because this method is designed to be used with a single measure with one value for useful life, it does not account for replacement costs. A measure is considered cost-effective if the simple payback (scalar ratio) is less than the scalar limit.

As an example, Table 4.5 shows the economic parameters used in the 90.1 Scalar Method for the Standard 90.1-2016 analysis. These parameters were adopted by the SSPC 90.1.

Table 4.5. Scalar Method Economic Parameters and Scalar Ratio Limit

\begin{tabular}{|l|c|c|}
\hline \multicolumn{1}{|c|}{ Input Economic Variables } & Heating & Cooling \\
\hline Economic Life - Years & \multicolumn{2}{|c|}{40} \\
\hline Down Payment $-\$$ & \multicolumn{2}{|c|}{$\$ 0.00$} \\
\hline Energy Escalation Rate - \%* & $\begin{array}{c}\text { NIST year-by-year } \\
\text { rates + 2.38\% inflation }\end{array}$ \\
\hline Nominal Discount Rate - \% & \multicolumn{2}{|c|}{$9.34 \%$} \\
\hline Loan Interest Rate - \% & \multicolumn{2}{|c|}{$7.0 \%$} \\
\hline Federal Tax Rate - \%** $\% \%$ \\
\hline State Tax Rate - \%** & \multicolumn{2}{|c|}{$0 \%$} \\
\hline Heating - Fossil Fuel ${ }^{\dagger}$ Price, \$/therm & $\$ 1.000$ & \multicolumn{2}{|c|}{$\$ 0.1013$} \\
\hline Cooling - Electricity Price, \$/kWh & $\mathbf{2 1 . 4}$ & $\mathbf{1 8 . 2}$ \\
\hline Scalar Ratio Limit &
\end{tabular}

* The NIST escalation rates are from the NIST 2013 supplement (Rushing et al. 2013). The real escalation rates are combined with an inflation rate for this nominal analysis.

** Tax rates are zero for 90.1-2016 because a nominal discount rate based on before-tax investments was selected.

$\dagger$ The ASHRAE Scalar Method identifies a fossil fuel rate that is primarily applied to heating energy use. For this reason, the fossil fuel rate is a

blended heating rate and includes proportional (relative to national heating fuel use) costs for natural gas, propane, heating oil, and electric heat. Heating energy use in the prototypes for fossil fuel equipment is calculated in therms based on natural gas equipment, but in practice, natural gas equipment may be operated on propane, or boilers that are modeled as natural gas may use oil in some regions.

DOE extends the Scalar Method to allow for the evaluation of multiple measures with different useful lives. This extended method takes into account the replacement of different components in the total package of Standard 90.1changes, allowing the NPV of the replacement costs to be calculated over 40 years. The SSPC 90.1 Envelope Subcommittee uses a 40-year replacement life for envelope components, and the useful lives of all other cost components in the cost estimate are less than that. For example, an item with a 20-year life would be replaced once during the study period. The residual value of any items with useful lives that do not fit evenly within the 40-year period is calculated using the method described in Section 4.1.2.3. Using this approach, the simple payback is calculated as the sum of the first costs and 
present value of the replacement costs, divided by the difference of the energy cost savings and incremental maintenance cost.

To determine cost-effectiveness, the result is compared to the scalar ratio limit for the 40-year period, 21.4 for heating or fossil fuels or 18.2 for electric or cooling, as shown in Table 4.5. For measures or evaluations that have a mixture of electric and fossil fuel savings, the separate scalar ratio limits are weighted by the proportion of each type of cost savings. The scalar ratio limit represents the simple payback for a 40-year life measure that would have a positive LCC using the other economic parameters shown. The packages of changes for each combination of prototype and climate location are considered cost-effective if the corresponding scalar ratio is less than the scalar ratio limit. The parameters shown in Table 4.5 are based on consensus of the SSPC 90.1.

\subsubsection{Detailed Discussion of Economic Parameters}

The meaning and source of each economic input parameter is discussed below. Where there are variations in the meaning or source for the different scenarios, these are discussed as well.

\subsubsection{Economic Study Period $(L)$}

DOE's economic analysis is intended to examine the costs and benefits impacting all the owners or tenants who use a commercial building and pay for energy use either directly or through a net lease. Because energy efficiency features may last longer than the average length of ownership or tenancy, a longer analysis period than the initial ownership period or tenancy is used. Assuming a single owner keeps the property throughout the analysis period accounts for long-term energy benefits without requiring complex accounting for resale values at property turnover. Commercial buildings will typically last 50 years or more. However, some energy efficiency measures may not last as long as the building does. Although 30 years is less than the life of the building, some efficiency measures, equipment in particular, may require replacement during that timeframe. As discussed earlier, when energy-saving equipment costs are analyzed, replacement costs will be included at the life of the equipment. The replacement costs are then discounted to present value as part of the cost. The impact of the selection of a study period is significantly moderated by the effect of the discount rate in reducing the value of costs and benefits far into the future.

DOE's methodology for Scenarios 1 and 2 is intended to assess cost-effectiveness based on a 30-year period of analysis or study period. The FEMP cost-effective methodology for federal buildings was amended by EISA to allow a study period of up to 40 years (42 U.S.C. 8254(a)(1)), while the DOE costeffectiveness method for commercial building codes uses 30 years. The 30 -year study period is used in the methodology for consistency with DOE's residential code cost-effectiveness analysis, and is also widely used for LCC analysis in government and industry. The study period is also a balance between capturing the impact of future replacement costs, inflation, and energy escalation and limiting uncertainty; the further into the future these costs are projected, the greater their uncertainty. The perspective of a single 30-year owner allows consideration of economic impacts on building owners or tenants, either single or multiple in succession, as well as consideration of long-term energy savings. While the full study period of 30 years is appropriate when analyzing the impact of an entire code, when individual measures are analyzed, a shorter study period equal to the measure life may be used. In this situation, the measure life will be determined based on measure life references. The primary reference is the ASHRAE 
HVAC Applications Handbook (ASHRAE 2011, p. 37.3), and secondary resources include the Database for Energy Efficient Resources (DEER), ${ }^{10}$ utility program guidelines (GDS 2007; KEMA 2009; Skumatz 2012), or Appendix J to the Oregon State Energy Efficient Design Guidelines (ODOE 2011).

Note that the parameters and methodology for Scenario 3, the ASHRAE 90.1 Scalar Method, are developed by the ASHRAE SSPC 90.1. A 40-year maximum study period is established by the SSPC for that method. For Scenario 3, a 40-year study period will be used, with the cost of interim replacements of shorter-lived equipment or measures added during the study period. This is a departure from the way the ASHRAE 90.1 Scalar Method is applied in the SSPC 90.1, and is necessary because typically DOE analyzes the entire code that contains multiple measures with different lives, while in the typical analysis for the ASHRAE SSPC 90.1, a single measure with a fixed life is analyzed. The 40-year life is the maximum used in SSPC analysis, typically for envelope measures.

\subsubsection{First Cost $(C)$}

As discussed earlier, the first cost represents the incremental cost of code-related energy features to a building owner. It represents the full (retail) cost of such features, including materials, sales tax ${ }^{11}$ on materials, labor, and contractor overhead and profit, but excludes any future costs such as for maintenance.

\subsubsection{Loan Interest Rate (i)}

Commercial real estate is highly leveraged, with less than $20 \%$ of funding from private investors (National Association of Realtors 2013). Accordingly, for the analysis of the economic benefits to the commercial building owners and tenants for improved energy efficiency, DOE intends to assume that buildings are purchased or refinanced using a loan. For simplification, no down payment is assumed in Scenarios 2 and 3. Scenario 1 does not evaluate loan impact.

For Scenario 2, DOE intends to use recent commercial loan rates in cost/benefit analyses, and will consult multiple online sources ${ }^{12}$ to determine a representative rate for each analysis. Recently, DOE used a commercial loan rate of 6\% for cost/benefit analyses of ASHRAE Standard 90.1 (Hart et al. 2013).

An alternative approach is to evaluate historical commercial loan rates and identify a real rate that approximates a long-term average, then use that rate in a real analysis or combine it with a recent (and anticipated future) inflation rate in a nominal analysis. DOE intends to use the former approach on the theory that recent rates are a better indicator of near-term future rates that will be in effect when a new code goes into effect. For Scenario 3, the loan rate is established by the ASHRAE 90.1 committee.

\footnotetext{
${ }^{10}$ The DEER is a California Energy Commission and California Public Utilities Commission sponsored database designed to provide well-documented estimates of energy and peak demand savings values, measure costs, and effective useful life all with one data source. See www.energy.ca.gov/deer/.

${ }^{11}$ Sales tax from online sources: http://taxfoundation.org/article/state-and-local-sales-tax-rates-2011-2013

${ }^{12}$ See www.realtyrates.com/commercial-mortgage-rates.html; www.commercialloandirect.com/commercialrates.php.
} 


\subsubsection{Loan Term $\left(M_{L}\right)$}

For the analysis of cost-effectiveness, the loan term will be set equal to the study period. While a typical commercial loan may be shorter, it is quite common for commercial buildings to be resold to a buyer who will take out a new loan or to be refinanced during their ownership period. While these are separate serial loans, the economic effect is similar to a single, longer-term loan.

\subsubsection{Discount Rate (D)}

The purpose of the discount rate is to reflect the time value of money. Because DOE's economic perspective is that of a building owner, that time value is determined primarily by the investor's best alternative investment at similar risk to the energy features being considered.

The discount rate is chosen to represent the desired perspective of the economic analysis, for Scenario 1, a public building owner, for Scenario 2, a private building owner or developer in a post-tax context, and for Scenario 3, a private building owner or developer in a pre-tax context.

For Scenario 1, DOE intends to use the real discount rate $\left(D_{r}\right)$ established annually in the NIST Handbook 135 Supplement for the FEMP analysis. For Scenario 2, DOE intends to set the nominal discount rate $\left(D_{n}\right)$ to be equivalent to the commercial loan interest rate (i). Because commercial lending is a viable source of funds for real estate investors, the associated loan rate is a reasonable estimate of an investor's alternative post-tax investment rate of return or discount rate. That real estate investors borrow money at that rate demonstrates that their implicit discount rate must be at least that high. As previously discussed, a real discount rate $\left(D_{r}\right)$ is also used in Scenario 2 for discounting items that experience inflation. The selection of that rate is discussed below under Inflation Rate and the type of discount rate used for different cash flows is shown in Table 4.4.

For Scenario 3, the nominal discount rate $\left(D_{n}\right)$ is established by the ASHRAE SSPC 90.1. As a point of comparison for the current parameters in Appendix A, the 9.34\% nominal discount rate in Scenario 3 is based on industry surveys of commercial real estate investors expected rate of return before taxes. While the $6.0 \%$ nominal discount rate for Scenario 2 appears lower, this is an after-tax discount rate, and if adjusted for a combined national and average state corporate income tax rate of 38.1\%, the effective pretax discount rate for Scenario 2 would be $9.7 \%$.

\subsubsection{Property Tax Rate $\left(R_{P}\right)$}

Property taxes vary widely within and among states. To determine a tax rate for analysis, DOE intends to use the average U.S. property tax rates (Lincoln Institute of Land Policy 2013) and weight them by rural and urban population ${ }^{13}$ and distribution of building size (EIA 2003) to arrive at a national weighted average. For current national level commercial code analysis, the resulting property tax rate is 2.04\%. For state level analyses, state-specific rates will be used.

\footnotetext{
${ }^{13}$ See https://ask.census.gov/faq.php?id=5000\&faqId=5971.
} 


\subsubsection{Income Tax Rate $\left(R_{T C}\right)$}

The marginal income tax rate paid by the building owner determines the value of the interest, property tax, and depreciation tax deductions. The combined effective $\left(R_{T C}\right)$, state $\left(R_{T S}\right)$, and federal $\left(R_{T F}\right)$ income tax rates are based on state taxes being deductible from federal taxes, as shown in Eq. (4). DOE intends to account for corporate income tax deductions in the cost/benefit analyses. The federal corporate tax rate currently varies from $15 \%$, transitioning to a $34 \%$ flat rate for incomes between $\$ 335,000$ and $\$ 10,000,000$ and then increasing to 35\% (IRS 2012b, p. 17). DOE's intends to use the flat rate for the next-to-highest tier of corporate income for their corporate income tax rate $\left(R_{T F}\right)$ estimate, currently 34\%. Should that tax structure change, the approach will be reevaluated. Where state corporate income taxes apply, rates will be taken from state sources or collections of state data such as those provided by the Federation of Tax Administrators. ${ }^{14}$

\subsubsection{Inflation Rate $\left(R_{I N F}\right)$}

An inflation rate is not needed in the real or constant dollar analysis in Scenario 1, and the inflation rate for Scenario 3 is determined by the ASHRAE SSPC 90.1. The inflation rate $R_{I N F}$ is used to determine a real discount rate $\left(D_{r}\right)$ for Scenario 2 . This real discount rate is applied to items that are subject to inflation as shown in Table 4.4. A long-term inflation rate appropriate for the study life is necessary. To capture a relatively constant long-term inflation rate over time that is appropriate for the study period, the inflation rate for the past 30 years will be applied to the next 30 years. Estimates of an annual inflation rate will be based on current $\left(C I_{C}\right)$ and past $\left(C I_{P}\right)$ indices from Producer Price Index (PPI) data published by the Bureau of Labor Statistics. ${ }^{15}$ The past $\left(C I_{P}\right)$ index is selected 30 years prior to the current $\left(C I_{C}\right)$ index. For the period since June 2004, ${ }^{16}$ "final demand construction” PPI data is used, normalized to "finished goods less food and energy" PPI data that is used for earlier periods. The equivalent compound inflation rate $\left(R_{I N F}\right)$ is calculated from the current $\left(C I_{C}\right)$ and past $\left(C I_{P}\right)$ construction indices as shown in Eq. (5).

$$
R_{I N F}=\left(\frac{C I_{C}}{C I_{P}}\right)^{1 / 30}-1
$$

The real discount rate $\left(D_{r}\right)$ for Scenario 2 is found based on the nominal discount rate $\left(D_{n}\right)$ as shown in Eq. (6).

$$
D_{r}=\left(\frac{1+D_{n}}{1+R_{I N F}}\right)-1
$$

\subsubsection{Energy Prices}

Energy prices over the length of the period of analysis are needed to determine the energy cost savings from improved energy efficiency. Both current energy prices and energy price escalation rates are needed to establish estimated energy prices in future years.

\footnotetext{
${ }^{14}$ Federation of Tax Administrators: www.taxadmin.org.

${ }^{15}$ Bureau of Labor Statistics. See www.bls.gov/.

16 "Final demand construction" PPI data was initiated in June 2004 and is not available for earlier periods.
} 
DOE will use the most recently available national annual average commercial energy prices from the EIA. Annual average prices are used to avoid selecting a short-term price that is subject to seasonal fluctuations. If energy prices from the most recent year(s) are unusually high or low, DOE may consider using a longer-term average of energy prices, such as the average from the past 3 years and projections for the next 2 years. For individual state analysis, DOE will use state annual average commercial energy prices from EIA.

\subsubsection{Energy Price Escalation}

Energy price escalation accounts for the fact that energy prices generally have increased faster than general inflation. Energy price escalation rates for Scenarios 1 and 2 will be obtained from the most recent projections in the NIST Handbook 135 Supplement to account for projected changes in energy prices. Currently, ASHRAE SSPC 90.1 uses the same escalation rates, and they will also be used for Scenario 3. Note that these escalation rates do not include inflation. Inflation is not necessary in Scenario 1 , as it is a current dollar or real discount analysis. In Scenario 2, the real discount rate is used rather than the nominal discount rate for energy savings, as the escalation does not include inflation. In the ASHRAE 90.1 Scalar Method, inflation is added to the future energy savings along with the escalation rate above inflation, and then a nominal discount rate is used to arrive at a present value. While each of these procedures appears different, they each arrive at the correct present value of energy savings based on the particular parameters and methods used in the scenario. 


\subsection{Aggregating Energy and Economic Results}

\subsection{Weighting Factors: Building Types and Climate Zones}

Simulation results for the building types and climate zones will be weighted based on weighting factors shown in Table 5.1 and Table 5.2, respectively. Weighting factors are based on disaggregated construction volume data from McGraw-Hill Construction (MHC) Project Starts Database. The MHC database contains the floor area of new construction in the United States for the years 2003 to $2007 .{ }^{1}$ PNNL analyzed this MHC database to develop detailed construction weights by building type, climate zones, and states (Jarnagin and Bandyopadhyay 2010). These weights are used in developing weighted national energy savings estimates. For each analysis, the weights are normalized for the prototypes used in the analysis so weightings total $100 \%$. These weighting factors are based on climate zones used through Standard 90.1-2013 and the 2015 IECC. Revisions that change the climate zones or switch to a new climate basis will require an update of the weighting factors or the development of a custom procedure to capture the impacts on national or state commercial energy efficiency.

\footnotetext{
${ }^{1}$ The 2003 to 2007 period represents a good time for commercial construction. Later data encountered a recession when commercial construction was curtailed. The database is used simply to represent characteristic weightings as a percentage of building types and locations, and is expected to be a valid predictor of commercial construction for the foreseeable future.
} 
Table 5.1. National Weighting factors by Prototype

\begin{tabular}{|l|r|r|}
\hline \multicolumn{1}{|c|}{ Prototype } & $\begin{array}{c}\text { Total Floor Area } \\
\times \mathbf{1 , 0 0 0} \mathbf{f t}^{2}\end{array}$ & $\begin{array}{c}\text { Construction } \\
\text { Weights }\end{array}$ \\
\hline Small Office & 371,009 & $4.50 \%$ \\
\hline Medium Office & 400,091 & $4.80 \%$ \\
\hline Large Office & 220,134 & $2.70 \%$ \\
\hline Standalone Retail & $1,009,246$ & $12.20 \%$ \\
\hline Strip Mall & 375,093 & $4.50 \%$ \\
\hline Primary School & 330,418 & $4.00 \%$ \\
\hline Secondary School & 685,508 & $8.30 \%$ \\
\hline Outpatient Healthcare & 289,171 & $3.50 \%$ \\
\hline Hospital & 228,131 & $2.80 \%$ \\
\hline Small Hotel & 113,837 & $1.40 \%$ \\
\hline Large Hotel & 327,562 & $4.00 \%$ \\
\hline Warehouse & $1,105,951$ & $13.40 \%$ \\
\hline Quick Service Restaurant & 38,809 & $0.50 \%$ \\
\hline Full Service Restaurant & 43,650 & $0.50 \%$ \\
\hline Mid-rise Apartment & 484,343 & $5.90 \%$ \\
\hline High-rise Apartment & 593,241 & $7.20 \%$ \\
\hline Covered by Prototypes & $6,616,193$ & $80 \%$ \\
\hline No prototype & $1,649,785$ & $20 \%$ \\
\hline Total & $8,265,977$ & $100 \%$ \\
\hline
\end{tabular}

Table 5.2. Commercial Weighting Factors by Climate Zone

\begin{tabular}{|c|c|c|c|}
\hline $\begin{array}{c}\text { Climate } \\
\text { Zone }\end{array}$ & $\begin{array}{l}\text { Thermal } \\
\text { Climate } \\
\text { Zone }\end{array}$ & $\begin{array}{c}\text { Moisture } \\
\text { Regime }\end{array}$ & $\begin{array}{c}\text { Overall } \\
\text { Location } \\
\text { Weight }\end{array}$ \\
\hline $1 \mathrm{~A}$ & 1 & Moist & $3.2 \%$ \\
\hline $2 \mathrm{~A}$ & \multirow{2}{*}{2} & Moist & $15.2 \%$ \\
\hline $2 B$ & & Dry & $3.0 \%$ \\
\hline $3 \mathrm{~A}$ & \multirow{3}{*}{3} & Moist & $15.0 \%$ \\
\hline $3 B$ & & Dry & $10.1 \%$ \\
\hline $3 \mathrm{C}$ & & Marine & $1.6 \%$ \\
\hline $4 \mathrm{~A}$ & \multirow{3}{*}{4} & Moist & $19.3 \%$ \\
\hline $4 \mathrm{~B}$ & & Dry & $0.5 \%$ \\
\hline $4 \mathrm{C}$ & & Marine & $3.0 \%$ \\
\hline $5 \mathrm{~A}$ & \multirow{2}{*}{5} & Moist & $19.4 \%$ \\
\hline $5 B$ & & Dry & $4.3 \%$ \\
\hline $6 \mathrm{~A}$ & \multirow{2}{*}{6} & Moist & $4.2 \%$ \\
\hline $6 \mathrm{~B}$ & & Dry & $0.6 \%$ \\
\hline 7 & 7 & N/A & $0.5 \%$ \\
\hline 8 & 8 & N/A & $0.1 \%$ \\
\hline
\end{tabular}




\subsection{Building Prototype Selection}

DOE may select a subset of the prototype buildings and simulate them in selected representative climate locations for the cost-effectiveness analysis to represent most of the energy and cost impacts of the code changes in a particular code or proposal analysis.

For example, for the Standard 90.1-2010 and 90.1-2013 national analyses, six of the prototype buildings were selected for cost estimate development in five climate locations, as shown in bold font in Table 5.3. The 6 prototypes selected provide a good representation of the overall code cost effectiveness, without requiring simulation of all 16 prototypes. ${ }^{2}$ DOE intends to continue to use these six prototypes unless a code change is identified that is not represented and has a large impact in one of the other prototypes. The resulting cost-effectiveness analysis from the six prototype analysis represents most of the energy and cost impacts of the changes in Standard 90.1. These six prototypes were chosen to represent the energy impact of five of the eight commercial principal building activities. The five represented principal building activities account for $74 \%$ of the new construction by floor area covered by the full suite of 16 prototypes.

Table 5.3. Prototype Buildings

\begin{tabular}{|l|l|c|}
\hline \multirow{4}{*}{ Principal Building Activity } & \multicolumn{1}{c|}{ Building Prototype } & $\begin{array}{c}\text { Included in Subset for Cost- } \\
\text { Effectiveness Analysis }\end{array}$ \\
\hline \multirow{4}{*}{ Office } & Small Office & Yes \\
\cline { 2 - 3 } & Medium Office & No \\
\cline { 2 - 3 } & Large Office & Yes \\
\hline \multirow{2}{*}{ Education } & Standalone Retail & No \\
\cline { 2 - 3 } & Strip Mall & Yes \\
\hline \multirow{3}{*}{ Healthcare } & Primary School & No \\
\cline { 2 - 3 } & Secondary School & No \\
\hline \multirow{2}{*}{ Lodging } & Outpatient Healthcare & No \\
\cline { 2 - 3 } & Hospital & Yes \\
\hline Warehouse & Small Hotel & No \\
\cline { 2 - 3 } & Large Hotel & No \\
\hline Food Service & Warehouse (non-refrigerated) & No \\
\hline Apartment & Quick-service Restaurant & No \\
\cline { 2 - 3 } & Full-service Restaurant & Yes \\
\cline { 2 - 3 } & Mid-rise Apartment & No \\
\cline { 2 - 3 } & High-rise Apartment & \\
\hline
\end{tabular}

\subsection{Represented HVAC Equipment Types}

To estimate the mix of energy types impacted by codes and the effect of different types of equipment, various water heating, space heating, and cooling equipment is selected for each prototype based on a typical application, with the goal of representing a broad cross section of the many commercial HVAC

\footnotetext{
${ }^{2}$ An analysis of the 6 prototype presented at the interim SSPC 90.1 meeting on October 19, 2011 showed savings
} for $90.1-2010 \mathrm{v}$. 2004 to be within $2.5 \%$ of the full set of 16 prototype analysis. 
and other systems used in the commercial building sector. The selections were vetted by building experts, including representatives of ASHRAE SSPC 90.1. The heating and cooling source and predominant and additional HVAC system types are shown in Table 5.4.

Table 5.4. HVAC Primary and Secondary Equipment

\begin{tabular}{|c|c|c|c|c|}
\hline \begin{tabular}{|c|} 
Building Prototype \\
\end{tabular} & Heating & Cooling* & Predominant System* & Additional System* \\
\hline Small Office & Heat Pump & Unitary DX & Packaged CAV & No \\
\hline Medium Office & Gas Furnace & Unitary DX & $\begin{array}{l}\text { Packaged VAV } \\
\text { w/Reheat }\end{array}$ & No \\
\hline Large Office & Boiler & $\begin{array}{l}\text { Chiller, Cooling } \\
\text { Tower }\end{array}$ & VAV w/Reheat & No \\
\hline Standalone Retail & Gas Furnace & Unitary DX & Packaged CAV** & No \\
\hline Strip Mall & Gas Furnace & Unitary DX & Packaged CAV** & No \\
\hline Primary School & Gas Furnace & Unitary DX & Packaged CAV** & No \\
\hline Secondary School & Boiler & Air-cooled Chiller & VAV w/Reheat & Packaged CAV \\
\hline Outpatient Healthcare & Boiler & Unitary DX & $\begin{array}{l}\text { Packaged VAV } \\
\text { w/Reheat }\end{array}$ & No \\
\hline Hospital & Boiler & $\begin{array}{l}\text { Chiller, Cooling } \\
\text { Tower } \\
\end{array}$ & VAV w/Reheat & Central CAV \\
\hline Small Hotel & Electricity & $\mathrm{DX}$ & PTAC & No \\
\hline Large Hotel & Boiler & Air-cooled chiller & Fan-coil Units & VAV w/Reheat \\
\hline Warehouse & Gas Furnace & Unitary DX & Unit Heater & Packaged CAV \\
\hline Quick-service Restaurant & Gas Furnace & Unitary DX & Packaged CAV & No \\
\hline Full-service Restaurant & Gas Furnace & Unitary DX & Packaged CAV** & No \\
\hline Mid-rise Apartment & Gas & DX & Split DX system & No \\
\hline High-rise Apartment & Boiler & Fluid Cooler & WSHP & No \\
\hline
\end{tabular}

* System abbreviations: DX = direct expansion; CAV = constant air volume; VAV = variable air volume;

PTAC $=$ packaged terminal air conditioners; WSHP = water source heat pump

** These systems are constant volume in 90.1-2007, and in some cases are VAV in 90.1-2010 and later

\subsection{Aggregation across Building Type and Climate Zone}

DOE may use one of two approaches to demonstrate overall cost-effectiveness for a code or standard edition as a whole.

- If all the individual building types and climate zones included in the analysis are found to be costeffective independently, using the metrics and scenarios applied, the overall cost-effectiveness is demonstrated.

- For situations where some building type and climate zone combinations do not meet cost-effective criteria, if the preponderance of individual building type and climate zones included in the analysis are found to be cost-effective independently, using the metrics and scenarios applied, the overall costeffectiveness is demonstrated even though a minority of the building type and climate zone combinations may not meet some economic criteria. To verify the impact in this case, DOE will aggregate the costs and savings on a national or state level. 


\subsubsection{National and State-Level Aggregations}

When energy code proposals are developed, they are typically shown to be cost-effective for situations and building types where they are likely to be applied. The proposal cost-effectiveness analysis does not usually cover all building types or climate zones. In combination with a sample-based costeffectiveness analysis, professional judgment of the consensus body is used to determine if a particular proposal is appropriate for addition to the standard or code. Proposals are also evaluated using national average energy prices, and the prices in some states can be lower. This means that for some building types in some climate zones, individual proposals may not be cost-effective. For individual code cycles, it is possible that some building type and climate zone combinations may not meet cost-effectiveness metric criteria, especially when analyzed at the state level with lower energy prices.

Individual results for building types in a climate zone can be aggregated to a national or state domain using weighting factors based on construction floor area for that domain. When a subset of climate zones or building types is selected for analysis, the weighting factors on each axis will be normalized so that the weightings for selected climate zones and building types each total $100 \%$. Individual results are then multiplied by the weighting factors to arrive at an aggregate result.

\subsubsection{Demonstration of Aggregate Cost-effectiveness}

For situations where some building type and climate zone combinations do not meet cost-effective criteria, the results for all the analyzed combinations will be weighted based on construction data. If the resulting cross-weighted cost-effectiveness metric for the commercial building set as a whole in the state or national domain analyzed meets the cost-effectiveness criteria, DOE will deem that cost-effectiveness has been demonstrated.

\subsection{Supplemental Range of Results or Sensitivity Analysis}

In some cases it may be desirable to understand the range of results that might occur given variation in some of the parameters. This type of analysis shows the sensitivity of the cost-effectiveness to each parameter and shows the range of possible results. This analysis can be conducted using either a Monte Carlo or discrete probability method. ${ }^{3}$ An example of such an analysis is shown in Appendix B. This type of analysis may help demonstrate the cost-effectiveness of a code or standard as a whole in a particular domain when some individual building type and climate zone combinations do not meet costeffectiveness criteria.

\footnotetext{
${ }^{3}$ A Monte Carlo analysis uses multiple random values of sensitive variables in an iterative analysis to find the range and distribution of possible outcomes, while a discrete probability method uses selected values that are assigned expected probabilities to determine an expected range of outcomes.
} 


\subsection{References}

10 CFR 436. "Methodology and Procedures for Life Cycle Cost Analyses.” Code of Federal Regulations. Available at http://www.gpo.gov/fdsys/pkg/CFR-2006-title10-vol3/pdf/CFR-2006-title10vol3-part436.pdf.

42 U.S.C. 8254(a)(1). ECPA, Public Law 94-385, as amended by the Energy Independence and Security Act of 2007 (EISA). Available at http://www.gpo.gov/fdsys/pkg/USCODE-2011-title42/html/USCODE2011-title42-chap91-subchapIII-partB.htm.

42 U.S.C. 6836 et seq. ECPA, Public Law 94-385, as amended. Available at http://www.gpo.gov/fdsys/pkg/USCODE-2011-title42/pdf/USCODE-2011-title42-chap81-subchapII.pdf.

ANSI/ASHRAE/IES Standard 90.1-2010. Energy Standard for Buildings Except Low-Rise Residential Buildings. American Society of Heating, Refrigerating and Air-Conditioning Engineers, Atlanta, GA.

ANSI/ASHRAE/IES Standard 90.1-2013. Energy Standard for Buildings Except Low-Rise Residential Buildings. American Society of Heating, Refrigerating and Air-Conditioning Engineers, Atlanta, GA.

ASHRAE Standard 169-2013. Climatic Data for Building Design Standards. American Society of Heating, Refrigerating and Air-Conditioning Engineers, Atlanta, GA.

ASHRAE. 2011. ASHRAE Handbook Applications. American Society of Heating, Refrigerating and Air-Conditioning Engineers, Atlanta, GA.

ASTM. 2010a. "Practice for Measuring Life-Cycle Costs of Buildings and Building Systems." E917, Annual Book of ASTM Standards: 2010, Vol. 4.11. ASTM International, West Conshohocken, PA.

ASTM. 2010b. "Practice for Measuring Net Benefits and Net Savings for Investments in Buildings and Building Systems.” E1074, Annual Book of ASTM Standards: 2010, Vol. 4.11. ASTM International, West Conshohocken, PA.

Briggs RS, RG Lucas, and ZT Taylor. 2003. "Climate Classification for Building Energy Codes and Standards: Part 2-Zone Definitions, Maps, and Comparisons.” ASHRAE Transactions 109(2).

DOE. 2012. "Building Energy Codes Program, Residential IECC Cost-effectiveness Analysis and Results”. U.S. Department of Energy, Washington, D.C. Accessed April 25, 2013 at http://www.energycodes.gov/development/residential/iecc_analysis.

EIA. 2003. Commercial Building Energy Consumption Survey. U.S. Department of Energy, Energy Information Administration, Washington, D.C. Available at www.eia.gov/consumption/commercial/data/2003/.

EIA. 2012. Short-Term Energy Outlook (STEO). U.S. Department of Energy, Energy Information Administration, Washington, D.C. Available at http://www.eia.gov/forecasts/steo/outlook.cfm and http://www.eia.gov/state/.

EIA. 2014. Short-Term Energy Outlook (STEO). U.S. Department of Energy, Energy Information Administration, Washington, D.C. Available at http://www.eia.gov/forecasts/steo/outlook.cfm and http://www.eia.gov/state/. 
EnergyPlus. 2011. Going with the Flow: Designing High-Performance Building with EnergyPlus. Available at http://www.energyplus.gov/.

Fuller S and S Petersen. 1995. Life-Cycle Costing Manual for the Federal Energy Management Program. National Institute of Standards and Technology, U.S. Department of Commerce, Washington, D.C.

GDS. 2007. Measure Life Report: Residential and Commercial/Industrial Lighting and HVAC Measures. Prepared for the New England State Program Working Group by GDS Associates, Inc., Manchester, NH. Available at http://library.cee1.org/sites/default/files/library/8842/

CEE Eval_MeasureLifeStudyLights\&HVACGDS 1Jun2007.pdf.

Halverson M, M Rosenberg, W Wang, J Zhang, V Mendon, R Athalye, Y Xie, R Hart, and S Goel. 2014. ANSI/ASHRAE/IES Standard 90.1-2013 Determination: Quantitative Analysis. Pacific Northwest National Laboratory, Richland, WA. Available at https://www.energycodes.gov/sites/default/files/ documents/901-2013_finalCommercialDeterminationQuantitativeAnalysis_TSD.pdf.

Hart R, J Boldt, and M Rosenberg. 2014a. "Pre-Cooling Chilled Water Return - Replacing Yesterday’s Strainer Cycle.” In ASHRAE Winter Conference Preprints CD. Presented at the ASHRAE Winter Meeting, New York, NY.

Hart R and Y Xie. 2014b. Cost-effectiveness of ASHRAE Standard 90.1-2013-Cost Estimate.xls. Pacific Northwest National Laboratory, Richland, WA. Available at http://www.energycodes.gov/sites/default/files/ documents/Cost-effectiveness_of_ASHRAE_Standard_90-1-2013-Cost_Estimate.zip.

Hart R, M Rosenberg, Y Xie, J Zhang, E Richman, DB Elliot, S Loper, M Myer. 2013. CostEffectiveness of ASHRAE Standard 90.1-2010 for the State of New York. Pacific Northwest National Laboratory, Richland, WA. Available at www.energycodes.gov/development/ commercial/cost_effectiveness.

ICC. 2014. “CP \#28-05 Code Development.” International Code Council, Washington, D.C. Accessed December 2014 at http://www.iccsafe.org/AboutICC/Documents/CP28-05.pdf.

IRS. 2012a. How To Depreciate Property. Publication 946, Internal Revenue Service, Washington, D.C.

IRS. 2012b. Corporations. Publication 542, Internal Revenue Service, Washington, D.C.

Jarnagin RE and GK Bandyopadhyay. 2010. Weighting Factors for the Commercial Building Prototypes Used in the Development of ANSI/ASHRAE/IES 90.1-2010. PNNL-19116, Pacific Northwest National Laboratory, Richland, WA. Available at www.pnl.gov/main/publications/external/technical_reports/ PNNL-19116.pdf.

KEMA. 2009. Focus on Energy Evaluation Business Programs: Measure Life Study Final Report: August 25, 2009. Prepared by KEMA for the State of Wisconsin Public Service Commission of Wisconsin, Madison, WI. Available at https://focusonenergy.com/sites/default/files/ bpmeasurelifestudyfinal_evaluationreport.pdf.

Lincoln Institute of Land Policy. 2013. Lincoln Institute of Land Policy and Minnesota Center for Fiscal Excellence, 50 State Property Tax Comparison Study. Cambridge, MA. Available at 
www.lincolninst.edu/subcenters/significant-features-property-tax/upload/sources/ContentPages/ documents/Pay_2012_PT_\%20Report_National.pdf.

McBride M. 1995. “Development of Economic Scalar Ratios for ASHRAE Standard 90.1 R.” In Proceedings of Thermal Performance of the Exterior Envelopes of Buildings VI, ASHRAE. American Society of Heating, Refrigerating and Air-Conditioning Engineers, Atlanta, GA. Available at http://consensus.fsu.edu/FBC/2010-Florida-Energy-Code/901_Scalar_Ratio_Development.pdf.

National Association of Realtors. 2013. Commercial Real Estate 2013 Lending Survey. Chicago, IL. Available at www.realtors.org/research-and-statistics.

NIST. 1995. Life-Cycle Costing Manual for the Federal Energy Management Program. NIST Handbook 135, U.S. Department of Commerce, Technology Administration, Washington, D.C., and National Institute of Standards and Technology, Gaithersburg, MD.

ODOE. 2011. Oregon State Energy Efficient Design (SEED) Guidelines. Oregon Department of Energy, Salem, OR. Available at http://www.oregon.gov/energy/CONS/SEED/Pages/Guidelines.aspx.

RS Means. 2014. RS Means Building Construction Cost Data, 72nd Ed. Construction Publishers \& Consultants, Norwell, MA.

Ruegg RT and SR Petersen. 1987. Comprehensive Guide to Least-Cost Energy Decisions. NBS Special Publication 709, National Bureau of Standards, Gaithersburg, MD.

Rushing A, J Kneifel, and B Lippiatt. 2013. Energy Price Indices and Discount Factors for Life-Cycle Cost Analysis-2013: Annual Supplement to NIST Handbook 135 and NBS Special Publication 709. NISTIR 85-3273-28, National Institute of Standards and Technology, Gaithersburg, MD.

Skumatz LA. 2012. Guidelines for the Development and Maintenance of Measure Lifetimes. Prepared for Regional Technical Forum, May 16, 2012, by Skumatz Economic Research Associates, Inc., Superior, CO. Available at http://rtf.nwcouncil.org/subcommittees/measurelife/RTF\%20Measure\%20 Useful\%20Life\%20Guidelines\%20Final\%202012\%200515.pdf.

Thornton B, M Halverson, M Myer, H Cho, S Loper, E Richman, D Elliott, V Mendon, and M Rosenberg. 2013. Cost-Effectiveness of ASHRAE Standard 90.1-2010 Compared to ASHRAE Standard 90.1-2007. PNNL-22972, Pacific Northwest National Laboratory, Richland, WA. Available at http://www.pnnl.gov/main/publications/external/technical_reports/pnnl-22972.pdf.

Thornton B, M Rosenberg, E Richman, W Wang, Y Xie, J Zhang, H Cho, V Mendon, and R Athalye. 2011. Achieving the 30\% Goal: Energy and Cost Savings Analysis of ASHRAE Standard 90.1-2010. PNNL-20405. Pacific Northwest National Laboratory, Richland, WA. Available at http://www.energycodes.gov/sites/default/files/documents/BECP_Energy_Cost_Savings_STD2010_May 2011_v00.pdf. 
Appendix A

\section{Current Cost-effectiveness Parameters}




\section{Appendix A}

\section{Current Cost-effectiveness Parameters}

\section{A.1 Commercial Cost-effectiveness Parameters}

Following the methodology outlined in this document and previously posted on the Building Energy Codes Program web site, ${ }^{1}$ the U.S. Department of Energy (DOE) has established the following parameters for analysis of current code proposals as of January 2015. Current economic parameters are posted at the same web site. These parameters are subject to reevaluation for each analysis and may change if deemed appropriate. The parameters used and their source will be documented in each analysis.

Table A.1. Summary of Current Economic Parameter Estimates

\begin{tabular}{|c|c|c|c|c|}
\hline Parameter & Symbol & $\begin{array}{c}\text { Scenario 1 } \\
\text { (Publicly-Owned } \\
\text { Method) } \\
\end{array}$ & $\begin{array}{c}\text { Scenario } 2 \text { (Privately- } \\
\text { Owned Method) }\end{array}$ & $\begin{array}{c}\text { Scenario } 3 \text { (ASHRAE } \\
\text { 90.1-2016 Scalar } \\
\text { Method) } \\
\end{array}$ \\
\hline Period of Analysis & $L$ & 30 years* & 30 years* & 40 years* \\
\hline Energy Prices & & \multicolumn{2}{|c|}{$\begin{array}{l}\text { Latest national annual average prices based on current } \\
\text { DOE Energy Information Administration (EIA) data** }\end{array}$} & $\begin{array}{l}\$ 0.1013 / \mathrm{kWh} \\
\$ 1.00 / \text { therm } \text { blend }^{\dagger}\end{array}$ \\
\hline Energy Escalation Rates & & $\begin{array}{l}\text { Price escalation rates } \\
\text { taken from } 2013 \text { NIST } \\
\text { Handbook } 135 \\
\text { Supplement }\end{array}$ & $\begin{array}{l}\text { National Institute of } \\
\text { Standards and Technology } \\
\text { (NIST) year-by-year rates } \\
\text { (same as scenario 1) }\end{array}$ & $\begin{array}{l}\text { NIST year-by-year } \\
\text { rates (same as scenario } \\
\text { 1) plus } 2.38 \% \text { inflation }\end{array}$ \\
\hline Loan Term & $M_{L}$ & N/A & $\begin{array}{l}M_{L}=L \text { (same as period of } \\
\text { analysis) }\end{array}$ & $\begin{array}{l}M_{L}=L \text { (same as period } \\
\text { of analysis) }\end{array}$ \\
\hline Loan Interest Rate & $I$ & N/A & $6.00 \%$ & $7.00 \%$ \\
\hline Nominal Discount Rate & $D_{n}$ & N/A & $6.00 \%$ (same as loan rate) & $9.34 \%$ \\
\hline Real Discount Rate & $D_{r}$ & $3.0 \%$ & $4.06 \%$ & $5.0 \%$ \\
\hline Inflation Rate & $R_{I N F}$ & N/A & $1.87 \%$ annual & $2.38 \%$ annual \\
\hline Property Tax Rate & $R_{P}$ & N/A & $2.04 \%$ & N/A \\
\hline Income Tax Rate, federal & $R_{T F}$ & N/A & $34.0 \%$ & $0 \%{ }^{\ddagger}$ \\
\hline Income Tax Rate, state & $R_{T S}$ & N/A & $\begin{array}{l}\text { State values vary; highest } \\
\text { marginal corporate rate used }\end{array}$ & $0 \%^{\ddagger}$ \\
\hline
\end{tabular}

* Study period shown is for full code or standard analysis, for individual measures, measure life may be used as the study period.

** Average EIA prices from EIA. State prices from EIA are used for individual state analysis. National analysis of Standard 90.1 may use the Scenario 3 prices established by ASHRAE.

$\dagger$ The ASHRAE Scalar Method identifies a fossil fuel rate that is primarily applied to heating energy use. For this reason, the fossil fuel rate is a blended heating rate and includes proportional (relative to national heating fuel use) costs for natural gas, propane, heating oil, and electric heat. Heating energy use in the prototypes for fossil fuel equipment is calculated in therms based on natural gas equipment, but in practice, natural gas equipment may be operated on propane, or boilers that are modeled as natural gas may use oil in some regions.

$¥$ Income tax rates are $0 \%$ for Scenario 3 because the current discount rate is based on pre-tax rate of return.

¥ Price escalation from Rushing et al. 2013.

\footnotetext{
${ }^{1}$ See http://www.energycodes.gov/development/commercial/methodology.
} 
Appendix B

\section{Supplemental Range of Results Method}




\section{Appendix B}

\section{Supplemental Range of Results Method}

In some cases, it may be desirable to understand the range of results that might occur in a costeffectiveness analysis, given potential variation in some of the parameters. This type of analysis shows the sensitivity of the cost-effectiveness to each parameter and shows the range of results that can occur. This analysis can be conducted using either a Monte Carlo or discrete probability method. This example uses a discrete probability or decision analysis method. This type of analysis may be helpful in demonstrating cost-effectiveness of a code or standard as a whole in a particular domain when some individual building type and climate zone combinations do not individually meet cost-effectiveness criteria.

\section{B.1 Evaluating Multiple Mixed Cost-effectiveness Results}

To demonstrate the Range of Results Method, two discrete probability analyses are conducted. The first shows the impact of variation in energy cost savings and construction costs and the second adds variation in economic parameters. For these examples, preliminary results of the analysis of ASHRAE Standard 90.1-2013 compared to 90.1-2010 are used. Note that this is intended to provide an example of the method, not a finished result. In a finished analysis, more research into each variable and the associated probabilities would be undertaken, and more documentation of that research, the data and expert sources used, and the range of each input parameter would be provided.

When conducting a national analysis, many parameters will vary from region to region and state to state. Variable parameters in the cost-effectiveness analysis include the following:

- Construction costs. Separate location cost factors for building envelope (walls and windows), lighting, and HVAC can be applied. In addition, sales tax varies from location to location and bid climate affects costs beyond average location multipliers. Replacement costs include a fairly large cost increase multiplier, and variation can be included for that cost as well. A variable reflecting bid climate is also included, as the number of active construction projects can have a large impact on local construction costs.

- Energy cost savings. A range of energy prices can be applied, along with multipliers on the escalation factors. In addition, a savings range can be applied, as there will be variation in savings in actual buildings compared with the prototype buildings.

- Economic parameters. While economic parameters have been established by federal statute or committee consensus process, there is variability in discount rates for various sectors and in the escalation rates for energy prices that can actually occur.

In a discrete probability analysis, a high, nominal, and low value for each factor is used (sometimes additional discrete states are added). Where a good set of data is available, these values and the probability of their occurrence can be determined fairly precisely, as is the case with occurrence of different state energy prices or sales taxes. In other cases, expert judgment can be applied to arrive at a reasonable range of values that are generally acceptable, and a reasonable set of probabilities can be 
applied. Even without a complete set of data-based inputs, a valid range of results can be shown, as individual high and low values tend to average out, and probabilities often match a standard distribution. The value of the analysis is not predicting a precise expected value, but is seeing the range of results that occurs with the given inputs and a good estimate for the expected value of the overall group result based on the given range of inputs. The expected value is similar to a weighted average, based on probability.

\section{B.2 Example of Variable Costs and Energy Parameters}

For this analysis, a weighted average net present value (NPV) savings of the six building types is used in Scenario 1. Variation in energy cost savings and construction cost values are analyzed.

An influence diagram shows the relationship of the parameters in this analysis:

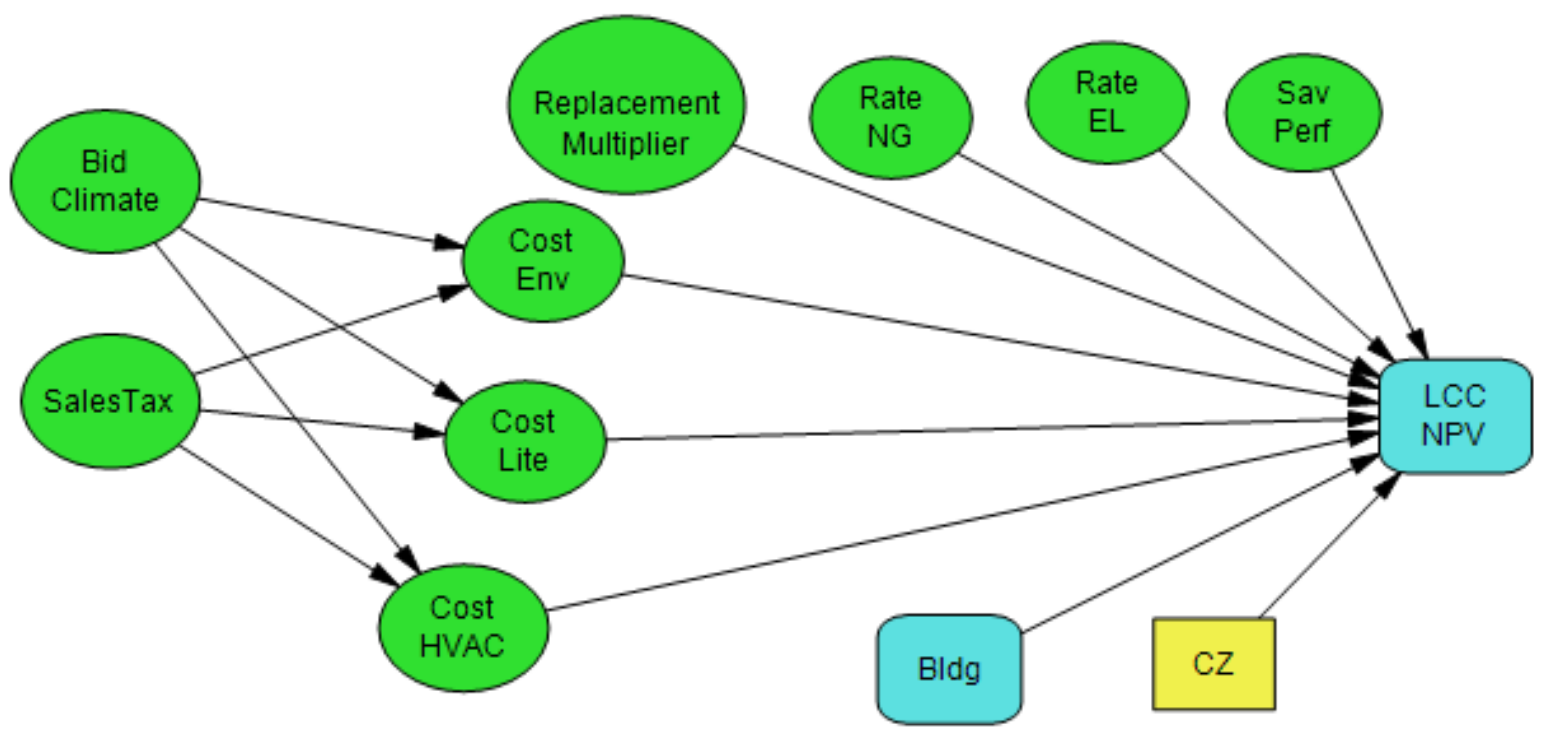

That relationship can also be seen as a decision tree, where the discrete states for each parameter are shown:

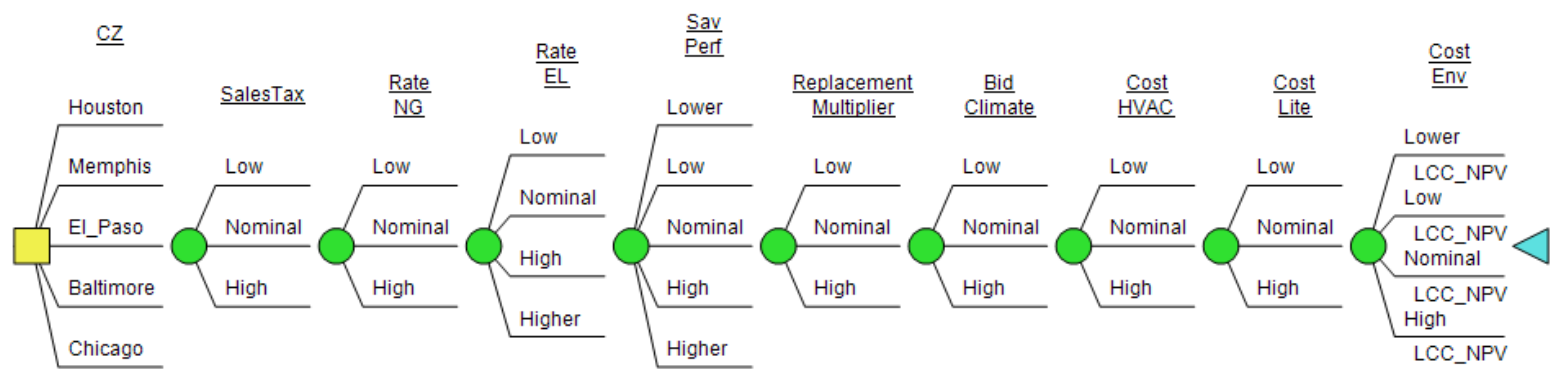

When the impact of the influencing parameters on the final NPV of savings is evaluated, we can see the range of impact each parameter has when the other parameters are held at their nominal state. The range of impact is displayed in a tornado diagram. The vertical line represents the NPV of savings for the 
Houston climate zone with all parameters equal to the nominal position. The width of each bar shows the high and low result that each parameter's range of values will produce when other influencing parameters are held at their nominal value. Reviewing the tornado diagram indicates that the electric rate and savings performance variation have the largest impact on the NPV of savings.

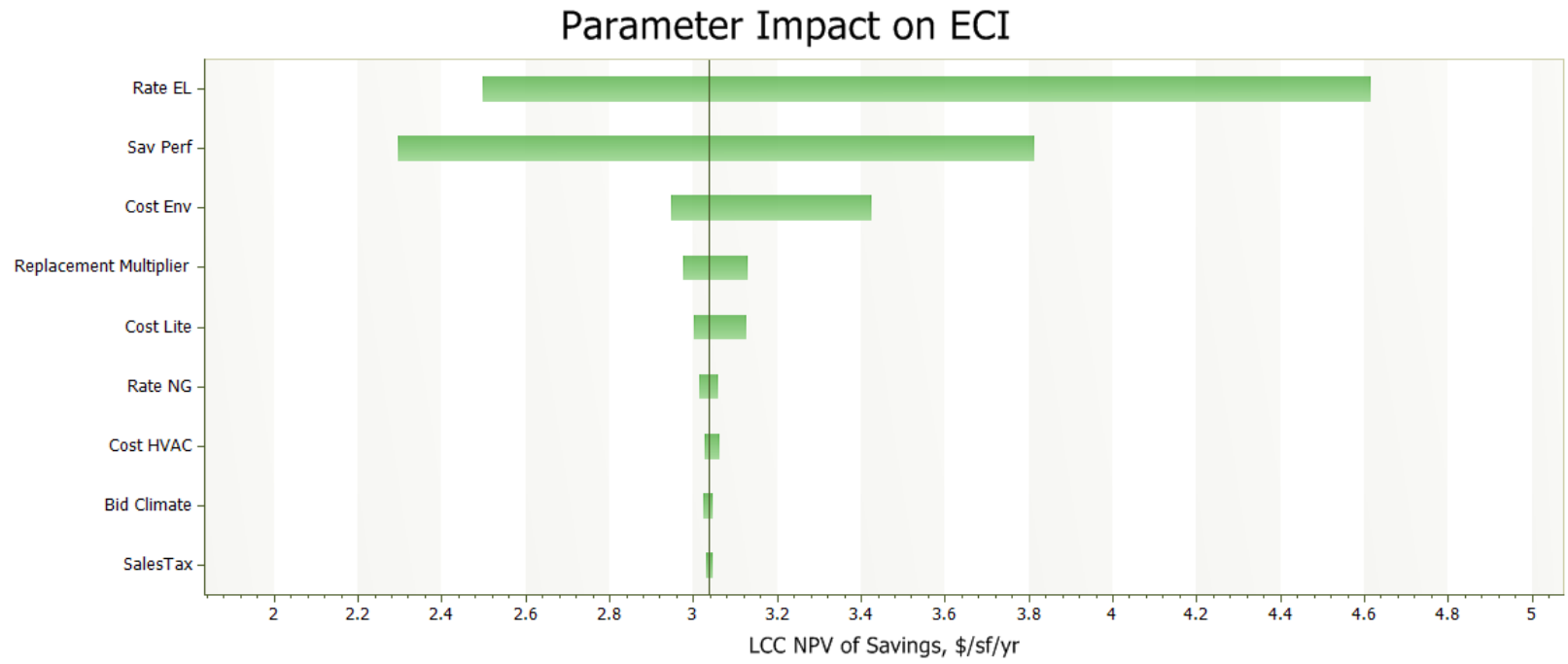

The range of NPV savings result can be viewed for individual climate zones, and a histogram for the weighted average of six building types in Baltimore, the location with the lowest NPV of savings result, is shown below.

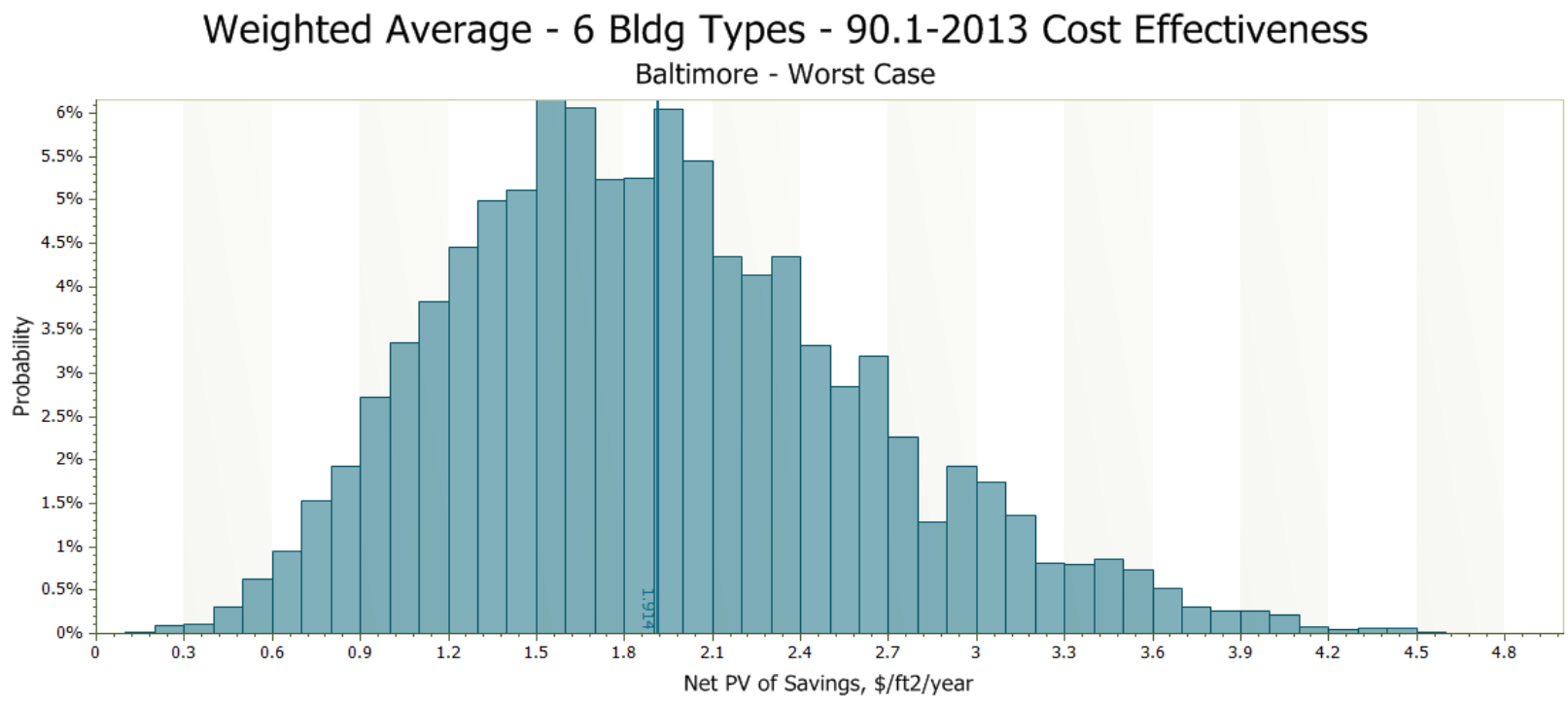


The histograms for each analyzed climate zone can be converted into a plot of cumulative probability, so they can be easily overlaid on one graph. The "S" shaped line shows the range of results and the vertical line shows the expected value, given the range and probabilities for all the input parameters.

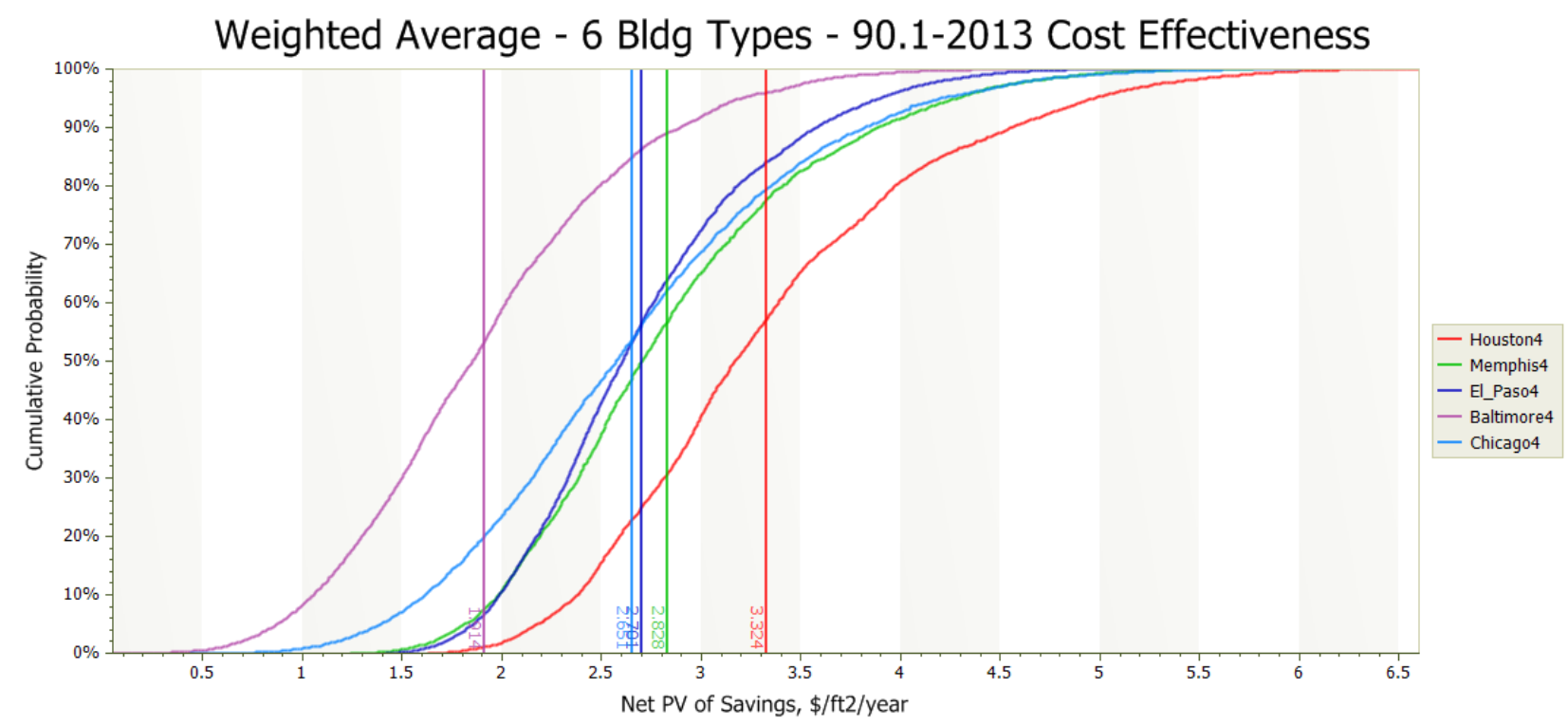

While in this example, the results across the entire range and combinations of parameter input in each climate zone analyzed were all cost-effective; in a case where some combinations fell below zero NPV savings, a code upgrade would be declared cost-effective as a whole if the expected value of NPV savings was greater than zero.

\section{B.3 Example including Variable Economic Parameters}

The previous example-based on preliminary results of the Scenario 1 analysis of Standard 90.12013 compared to 90.1-2010 — can be expanded to include variation in the energy price escalation rates and discount rate used. Again, this analysis is intended to provide an example of the method, not a finished result. In a finished analysis, more research into each variable and the associated probabilities would be undertaken, and more documentation of that research and the selected range of parameter inputs would be provided. 
There are often uncertainties regarding the predicted energy escalation rates and the discount rates used in the analysis. While these are established by federal regulation for federal projects, a view of the impact of varying those rates may be helpful from the private investment view. For illustration, the previous analysis was revised to include influence of varying the energy price escalation rates from $80 \%$ to $120 \%$ of their value as established by the Energy Information Administration and look at real discount rates from $0.5 \%$ to $7.0 \%$ rather than just $3.0 \%$. The revised influence diagram is shown below:

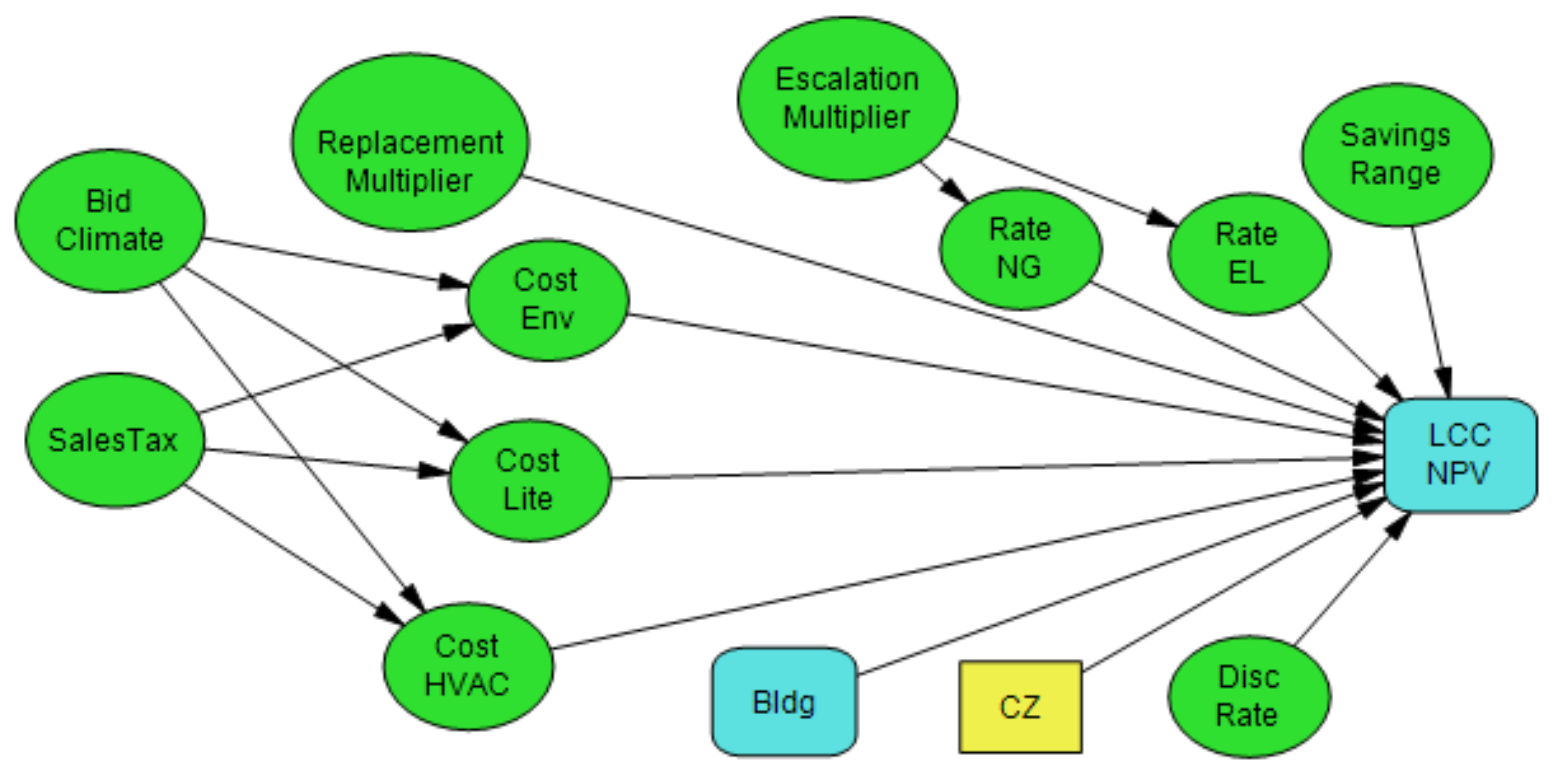

When a sensitivity analysis is run for the Houston climate zone, the energy price escalation multiplier does have a large impact, and the discount rate variation has a lesser impact.

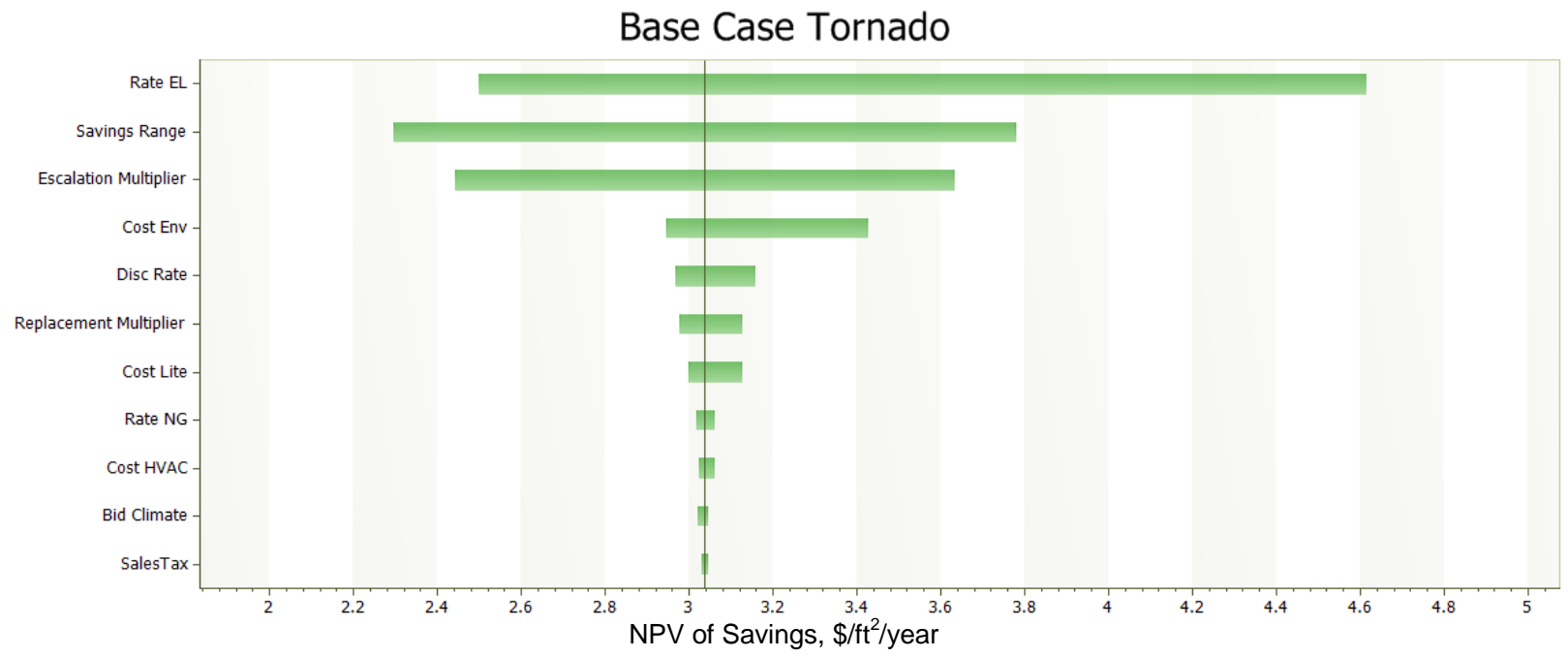


Looking at the cumulative probability diagram for the weighted results of all six building types, we can see that the purple line for the Baltimore climate zone extends below zero NPV, because there are some combinations of the tested parameters that result in a NPV of savings less than zero; however, the preponderance of cases still have a positive net savings, and the expected values of NPV savings shown by the vertical lines for all climate zones are greater than zero. In fact the probability is so low that NPV is less than zero it is difficult to see the tail of the line for Baltimore on the chart. So a conclusion can be made that the code as a whole is cost-effective, even with savings, cost, and economic parameter input variation.

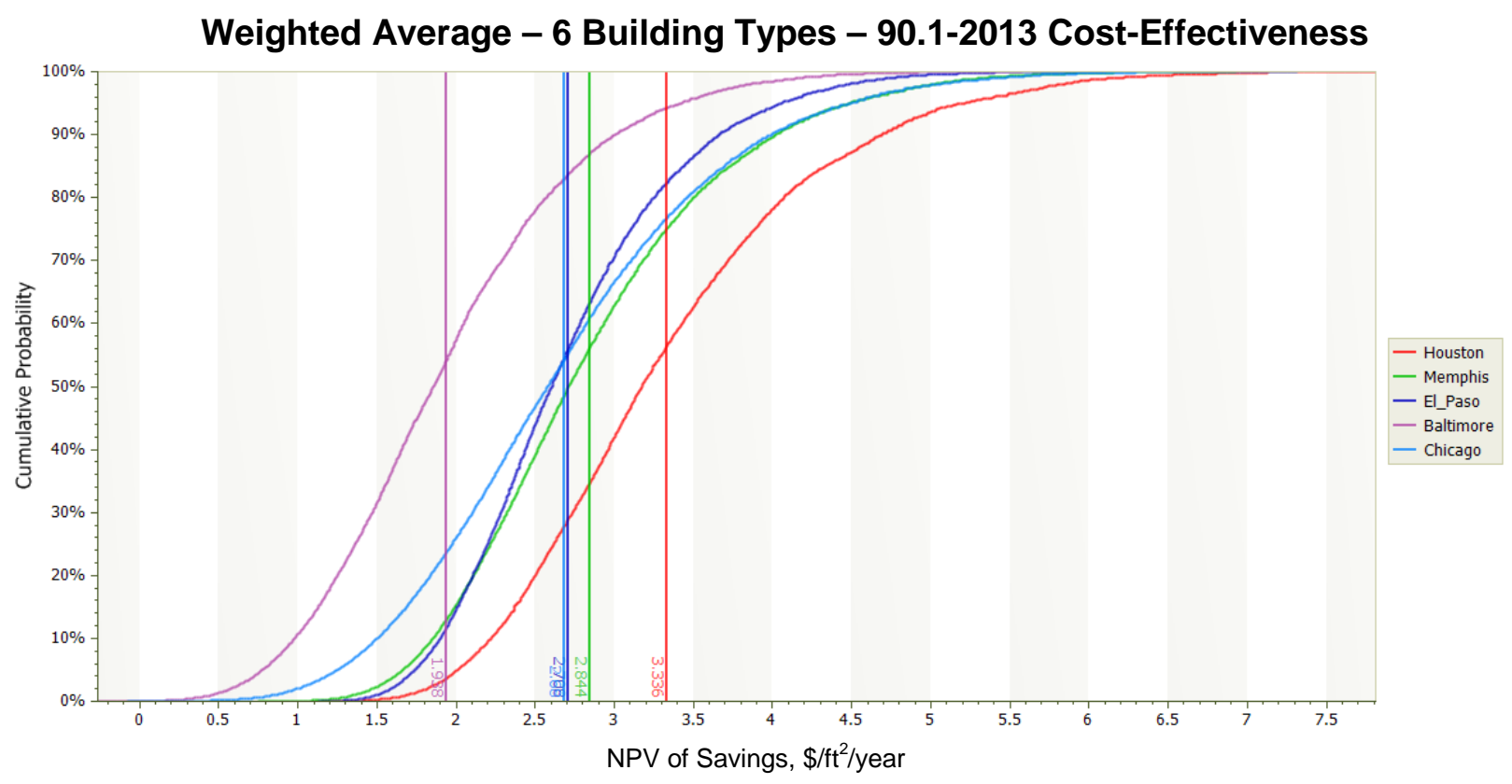



The U.S. Department of Energy's Building Energy Codes Program is an information resource on national model energy codes. We work with other government agencies, state and local jurisdictions, national code organizations, and industry to promote stronger building energy codes and help states adopt, implement, and enforce those codes.

BECP Website

Www.energycodes.gov

BECP Technical Support techsupport@becp.gov

www.energycodes.gov/support/helpdesk.php

\section{EERE Information Center}

1-877-EERE-INF (1-877-337-3463)

www.eere.energy.gov/informationcenter

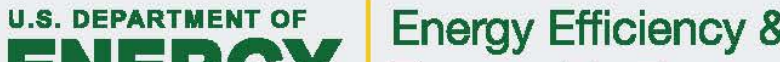 Renewable Energy}

